\title{
A Circuit for Detection of Interaural Time Differences in the Brain Stem of the Barn Owl
}

\author{
C. E. Carr and M. Konishi \\ Division of Biology, California Institute of Technology, Pasadena, California 91125
}

Detection of interaural time differences underlies azimuthal sound localization in the barn owl Tyto alba. Axons of the cochlear nucleus magnocellularis, and their targets in the binaural nucleus laminaris, form the circuit responsible for encoding these interaural time differences. The nucleus laminaris receives bilateral inputs from the cochlear nucleus magnocellularis such that axons from the ipsilateral cochlear nucleus enter the nucleus laminaris dorsally, while contralateral axons enter from the ventral side. This interdigitating projection to the nucleus laminaris is tonotopic, and the afferents are both sharply tuned and matched in frequency to the neighboring afferents.

Recordings of phase-locked spikes in the afferents show an orderly change in the arrival time of the spikes as a function of distance from the point of their entry into the nucleus laminaris. The same range of conduction time (160 $\mu \mathrm{sec})$ was found over the $700-\mu \mathrm{m}$ depth of the nucleus laminaris for all frequencies examined (4-7.5 $\mathrm{kHz}$ ) and corresponds to the range of interaural time differences available to the barn owl. The estimated conduction velocity in the axons is low (3-5 $\mathrm{m} / \mathrm{sec})$ and may be regulated by short internodal distances $(60 \mu \mathrm{m})$ within the nucleus laminaris.

Neurons of the nucleus laminaris have large somata and very short dendrites. These cells are frequency selective and phase-lock to both monaural and binaural stimuli. The arrival time of phase-locked spikes in many of these neurons differs between the ipsilateral and contralateral inputs. When this disparity is nullified by imposition of an appropriate interaural time difference, the neurons respond maximally. The number of spikes elicited in response to a favorable interaural time difference is roughly double that elicited by a monaural stimulus. Spike counts for unfavorable interaural time differences fall well below monaural response levels.

These findings indicate that the magnocellular afferents work as delay lines, and the laminaris neurons work as coincidence detectors. The orderly distribution of conduction times, the predictability of favorable interaural time differences from monaural phase responses, and the pattern of the anatomical projection from the nucleus laminaris to the

\footnotetext{
Received Nov. 3, 1989; revised May 4, 1990; accepted May 9, 1990.

We wish to thank Ted Sullivan, Larry Proctor, and Hermann Wagner for helpful discussions and for the computer programs used in this study. We gratefully acknowledge Ad Aertsen, Andy Moiseff, Ed Rubel, Susan Volman, Hermann Wagner, Tom Yin, and two anonymous referees for their thoughtful criticisms of this manuscript. This work was supported by NRSA Grant 07475 to C.E.C. and NIH Grant NS 14617 to M.K.

Correspondence should be addressed to Dr. Catherine Carr, Department of Zoology, 1200 Zoology-Psychology Building, University of Maryland, College Park, MD 20742-4415.

Copyright (C) 1990 Society for Neuroscience $0270-6474 / 90 / 103227-20 \$ 03.00 / 0$
}

central nucleus of the inferior colliculus suggest that interaural time differences and their phase equivalents are mapped in each frequency band along the dorsoventral axis of the nucleus laminaris.

Barn owls are nocturnal predators that can localize prey by auditory cues alone (Payne, 1971; Konishi, 1973). When a sound originates away from the midsagittal plane of the owl's head, it reaches one ear before the other, with a resulting interaural time difference or ITD. Behavioral experiments have shown that the owl uses these ITDs to localize sound in azimuth (Moiseff and Konishi, 1981; Moiseff, 1989a, b). In this paper, we describe the brain-stem circuit that encodes and measures these time differences.

The owl derives ITDs from the interaural phase differences present in the auditory stimulus (Moiseff and Konishi, 1981; Takahashi and Konishi, 1986). Phase information is preserved in the phase-locked firing of the eighth nerve and conveyed to the magnocellular cochlear nucleus via large end-bulb synapses (Brawer and Morest, 1975; Konishi et al., 1985). Detection of interaural differences begins in the nucleus laminaris, which receives input from the magnocellular cochlear nuclei (Takahashi and Konishi, 1988a). The nucleus laminaris is thought to be the avian homolog of the mammalian medial superior olive and, like the olive, contains neurons that are sensitive to ITDs (Goldberg and Brown, 1969; Moiseff and Konishi, 1983; Sullivan and Konishi, 1986; Yin and Chan, 1988, 1990).

The nucleus laminaris receives a bilateral projection from the nucleus magnocellularis (Takahashi and Konishi, 1988a). The circuit in the nucleus laminaris established by these magnoccllular afferents resembles that required by Jeffress' place theory of sound localization (Jeffress, 1948; Licklider, 1959; Carr and Konishi, 1988; Konishi et al., 1988). The Jeffress model is composed of 2 elements: coincidence detectors and delay lines. The coincidence detectors are binaural neurons that respond maximally when they receive simultaneous inputs from both ears. They are innervated by delay lines and respond maximally when an ITD is exactly compensated for by a delay introduced by the pattern of innervation. We have published a preliminary account of the role of the magnocellular afferents in the measurement of ITDs (Carr and Konishi, 1988). In the present paper, more complete data and analysis show that magnocellular axons act as delay lines, and that laminaris neurons act as coincidence detectors, to form a circuit in the nucleus laminaris that measures and encodes ITDs.

\section{Materials and Methods}

Results were obtained from 13 adult barn owls (Tyto alba) of both sexes. Most owls were also used in parallel studies (Takahashi et al., 1987; Carr and Konishi, 1988; Fujita, 1988). 


\section{Anatomy}

HRP was used as an extracellular, anterograde tracer to study the projections of the nucleus magnocellularis in 6 owls. The birds were anesthetized by intramuscular injection of ketamine hydrochloride $(4 \mathrm{mg} /$ $\mathrm{kg} / \mathrm{hr}$; Vetalar, Bristol) and Valium $(1.5 \mathrm{mg} / \mathrm{kg} / \mathrm{hr})$. They were $\mathrm{kept}$ warm with a heating pad and held in a comfortable horizontal position. The skull was immobilized by placing the owl in a stereotaxic head holder. A stainless-steel head plate was cemented to the skull to hold the head at the angle originally set by the head holder, and a reference post was glued onto the skull at the intersection of the interaural axis and the midline of the skull. The dural surface above the posterior forebrain was exposed after a craniotomy. Following the craniotomy, a small hole was made in the dura mater, and the nucleus magnocellularis was stereotaxically and physiologically identified using glass electrodes filled with $0.5 \mathrm{~m} \mathrm{Na}$ acetate. Sufficient neural activity was recorded through the electrodes to identify the best frequency of the recording site. Extracellular injections of HRP into the nucleus magnocellularis were then made with similar glass electrodes of $20-40 \mu \mathrm{m}$ diameter, filled with HRP (Boeringer-Mannheim) in filtered 0.5 $\mathrm{M} \mathrm{KCl}$-Tris buffer (pH, 7.6). HRP was iontophoresed with about $2 \mu \mathrm{A}$ pulsed positive current for 4-10 $\min$. After the experiment, the craniotomy was sealed with dental cement, and the scalp was sutured after application of a local anesthetic. Antibiotic cream (Neosporin) was applied to the wound, and the owl was returned to its recovery box. These procedures served to reduce discomfort and prevent infection. Usually, the owl recovered fully and was able to eat within $12 \mathrm{hr}$. If the owl did not eat, it was given subcutaneous injections of glucose and saline until it recovered. Twentyfour hr to 3 days after the HRP injection, the owls were anesthetized with Ketamine, followed by a lethal dose of Nembutal $(35 \mathrm{mg} / \mathrm{kg}$, i.m.; Abbott). After intracardial injection of heparin, owls were transcardially perfused with saline, followed immediately hy 1 liter $1.25 \%$ glutaraldehyde and $2 \%$ paraformaldehyde in $0.1 \mathrm{~m}$ phosphate buffer $(\mathrm{pH}, 7.2)$. The brain was postfixed overnight at $4^{\circ} \mathrm{C}$, then sectioned at $100 \mu \mathrm{m}$ in cold phosphate buffer on a vibratome. Sections were processed with diaminobenzidine as a chromagen (Adams, 1981). Several of the bestlabeled fibers were reconstructed with the aid of a camera lucida using the method of Sereno (1985), as previously described (Carr and Konishi, 1988). Axon path lengths were measured from these camera lucida drawings using a modified version of a morphometric data-collection program, which allowed the incorporation of section-thickness data into axon-length measurement (Curcio and Sloan, 1986). Measurements of axon length, diameter, and internodal distance were also obtained from the best-labeled fibers. In all size estimations, no correction was made for tissue shrinkage. There is also a constant error of $0.2 \mu \mathrm{m}$ in all single measurements because of the limits of resolution with the light microscope. Despite the possibilities of artifact, there is generally good agreement between measurements made from HRP material and that examined with other techniques (Cullheim and Kellerth, 1978).

Six of 7 owls used in neurophysiological studies also received small HRP injections (about $2 \mathrm{nA}, 5 \mathrm{~min}$ ) to mark the dorsal and ventral borders of the nucleus laminaris. A description of how the nucleus laminaris was localized may be found in the Results section (see Fig. 6). The owls were deeply anesthetized with Nembutal and killed at the end of each experiment.

\section{Physiology}

Surgery. Owls were anesthetized as above for neurophysiological recording, and the skull was immobilized by placing the owl in a stereotaxic head holder such that the plane defined by the center of the ear bars and the ventral surface of the palatine ridge was inclined down by $70^{\circ}$ from the horizontal. This plane is distinct from the plane normal to the owl's visual axes employed in other owls in this and previous studies, where the beak is inclined by $45^{\circ}$ (Knudsen, 1983; Takahashi and Konishi, 1988b; Fig. 1 shows a section at the $45^{\circ}$ plane). The new plane was chosen so that our electrodes penetrated the nucleus laminaris parallel to the magnocellular afferents. The dorsal surface of the brain stem was exposed by removal of the overlying cerebellum. Cerebellar tissue was removed by aspiration on one side of the midline sinus. This opening was then enlarged to expose most of the nucleus laminaris on the side contralateral to the hole. The nucleus laminaris slopes upwards on each side of the midline, and the diagonal cavity allowed us to angle the electrode by $45^{\circ}$ in the mediolateral plane to penetrate the nucleus laminaris orthogonal to its surface and parallel to the interdigitating afferents (see Figs. 1,6). The correct head and electrode angles were determined in preliminary experiments and checked by HRP injections as described above. Each penetration was marked on a drawing of the floor of the fourth ventricle, using the distinctive patterns of blood vessels as a guide to the approximate mediolateral position and best frequency of the underlying nucleus laminaris. The dorsal surface of the nucleus magnocellularis was visible at the caudal portion of the hole. Because the size of the cerebellar opening was limited, we were not able to penetrate the most lateral portions of nucleus laminaris at the correct angle (see Fig. 4). Furthermore, because of the physical constraints of the stereotaxic apparatus, we always recorded from the nucleus laminaris on the right side of the owl.

Stimuli. The response properties of the neurons were determined using tone-burst stimuli, while wide-band noise was used as a search stimulus. Sounds were delivered at a rate of 2 stimuli per sec through carphones inserted in the external auditory meatus. Sine waves were generated by a General Radio 1310 -B oscillator, and noise signals were produced by a custom-built noise generator. Stimuli were either 100 or $300 \mathrm{msec}$ in duration (rise and decay time, $5 \mathrm{msec}$ ) and shaped by an electronic switch. A digital delay circuit (Moiseff and Konishi, 1981) controlled ITD over a $\pm 300-\mu \mathrm{sec}$ range with a sampling interval of 30 $\mu \mathrm{sec}$, where + and - indicate the ipsilateral (right) ear and the contralateral (left) ear leading, respectively. The earphone assembly that was inserted in the ear canal contained a calibrated microphone (Knowles BT-1752) with a probe tube. Sound pressure near the eardrum was initially measured with a Bruel and Kjaer $1 / 2$-inch microphone with a probe tube inserted through a hole made on the exoccipital bone so that the output of the Knowles microphone could be translated into sound pressure near the eardrum. For computer-controlled frequency tuning, the computcr adjusted sound level with digital attenuators according to the stored frequency-response characteristics of the earphones and ear cavity (Wagner et al., 1987). For manual control of sound pressure, the output of the oscillator was adjusted to produce approximately $74 \mathrm{~dB}$ SPL between 3 and $9 \mathrm{kHz}$ when the manual attenuators were set to 0 $\mathrm{dB}$. The phase responses of the 2 earphones did not differ by more than $7 \mu \mathrm{sec}($ at $6667 \mathrm{~Hz}$ ). Stimulus amplitude was approximately $40 \mathrm{~dB}$ SPL in all cases, or between 10-20 dB above the threshold of the neuron. The interaural intensity was set to 0 in all experiments.

Electrophysiology. All data were obtained by intracellular methods. This both allowed measurement of spikes within the nucleus laminaris and obviated the difficulties of extracellular recordings in the nucleus laminaris. Action potentials from single neurons in the nucleus laminaris are masked by the overwhelming field potential termed the neurophonic (Sullivan and Konishi, 1986). Similar difficulties have been found in recording from the mammalian medial superior olive (Guinan et al., 1972). Action potentials were recorded with a WPI M701 DC amplifier. The action potentials were then amplified, filtered, and discriminated by an AC amplifier with a built-in level discriminator that generated computer-compatible pulses. The time of occurrence of these pulses was recorded and analyzed with a PDP $11 / 40$ computer. On occasion, the DC signal was also recorded on FM tape and later photographed with a Grass kymograph camera. The best frequency of each neuron was determined with the aid of an audio monitor. These measures of best frequency were confirmed on several occasions by analyzing selected neurons with a tuning program (Manley et al., 1988) to obtain isointensity rate functions (see Figs. 3, 16B). Our measures of best frequency were always within $100 \mathrm{~Hz}$ of those obtained by this tuning program.

Data analysis. The eighth nerve and the magnocellular and laminaris neurons respond at a particular phase angle of a sinusoidal stimulus. Such phase angles can be measured in period histograms, which show the probability of an action potential occurring at different phase angles during each tonal period (Goldberg and Brown, 1969). The vector strength and mean phase of the units were calculated by the method of Goldberg and Brown (1969). Period histograms constituted responses to 30,000 stimulus cycles, and contained between 500 and 2500 spikes. Period histograms were used to calculate conduction delay in magnocellular afferents within the nucleus laminaris in 2 different ways (Carr and Konishi, 1988). With the first method, we used phase-frequency plots to obtain a measure of latency (Anderson et al., 1970; Yin and Kuwada, 1983; see Fig. 9). The second method for calculating conduction delay measured mean phase at a single stimulus frequency for all neurons recorded during a single penctration. This enabled us to compare patterns of phase shifts among neurons recorded in a single penetration and to compare phase data for selected frequencies between $4-7.5 \mathrm{kHz}$ from many different penetrations. The tonotopic arrangement of neurons enabled us to place the electrode accurately in the isofrequency 


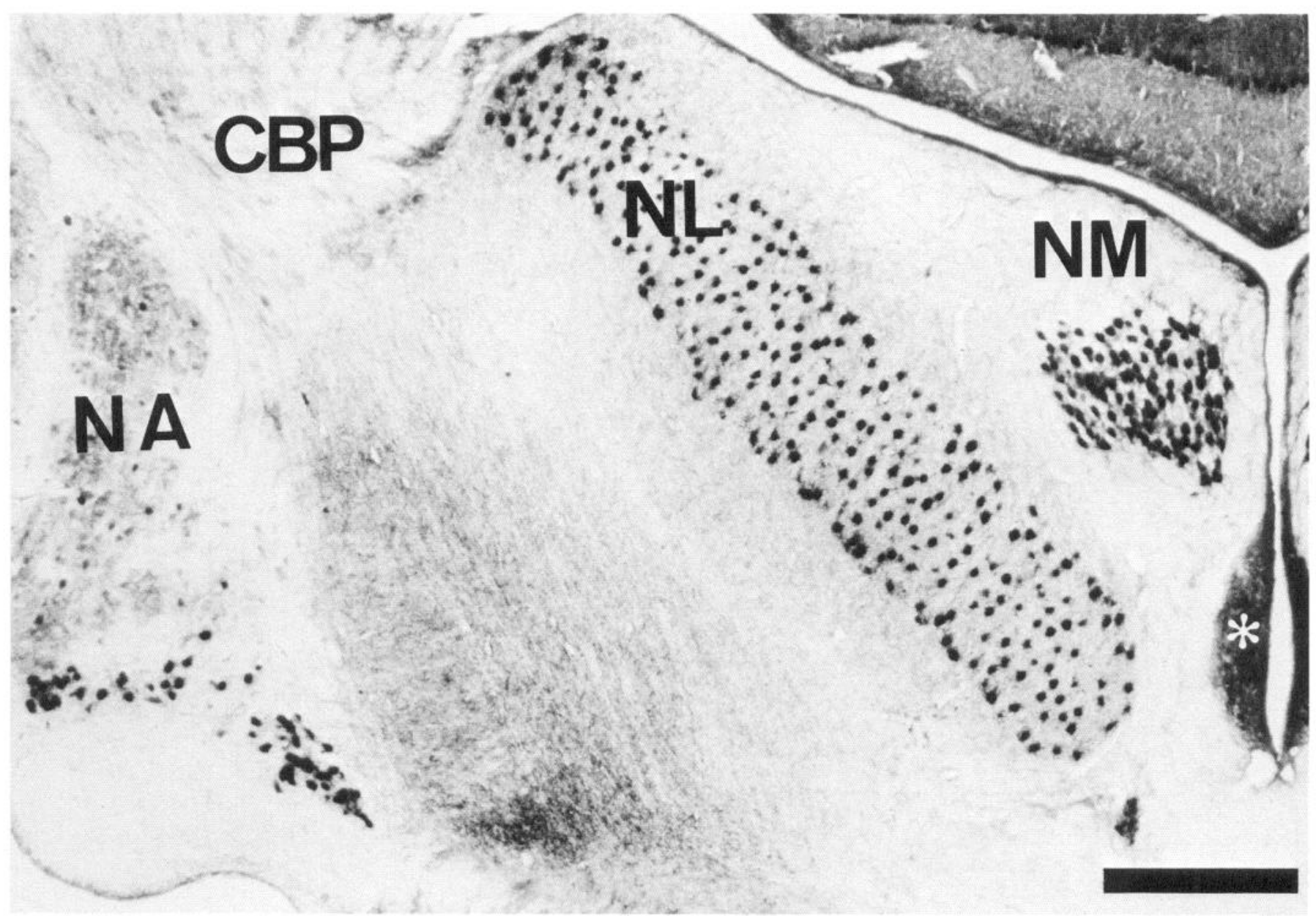

Figure 1. Transverse section through barn owl brain stem stained with monoclonal antibody that recognizes calretinen. This photomicrograph shows both the cochlear nuclei $(N A, N M)$ and the nucleus laminaris $(N L)$. The medial vestibular nucleus $\left(^{*}\right)$ forms the medial border and the cerebellar peduncle $(C B P)$ forms the lateral border of the nucleus laminaris. Scale bar, $700 \mu \mathrm{m}$.

lamina that contained neurons tuned to the selected stimulus frequency. Furthermore, we determined the best frequency of each fiber in each penetration and, if it changed with depth by more than $250 \mathrm{~Hz}$, data from the penetrations were not used in our analysis.

We plotted the mean phase of each magnocellular afferent against the depth at which it was recorded within the nucleus laminaris for each penetration. Only penetrations with at least 5 separate intracellular recordings (mean, 10 recordings) from magnocellular axons within the nucleus laminaris were used, and only those afferents with vector strength values greater than 0.2 were included in the analysis. Recordings with low vector strength usually resulted from unstable recordings and were excluded from analysis. A regression line was calculated for each plot for both ipsi- and contralateral afferents (see Figs. 7, 8), and the slope was used to calculate condition velocity $(\mu \mathrm{m} / \mu \mathrm{sec})$ by converting change in phase with depth to change in time with depth. For example, a $180^{\circ}$ phase shift at $5 \mathrm{kHz}$ was converted to a $100 \mu \mathrm{sec}$ change in delay.

The measurement of ITD sensitivity has been previously described (Goldberg and Brown, 1969). After determining the best frequency by listening to an audiomonitor, ITDs were measured with 5 repetitions of each stimulus. These responses were combined and normalized to the maximum response. Mean ITDs were then calculated (Takahashi and Konishi, 1986).

\section{Results}

Bilateral nucleus magnocellularis projection to the nucleus laminaris

The nucleus magnocellularis and the nucleus laminaris form a large part of the dorsal surface of the brain stem in the barn owl. The nucleus magnocellularis is more medial and caudal than the nucleus laminaris, though the 2 nuclei overlap over a part of their range (Figs. 1, 2, 3A). The nucleus laminaris is situated on the floor of the fourth ventricle and is bordered on its dorsal surface by a superficial fiber layer of eighth-nerve axons and a deep layer of axons from the ipsilateral nucleus magnocellularis. The ventral border of the nucleus laminaris is composed of afferents from the contralateral nucleus magnocellularis. These 2 fiber layers sandwich the neuropil of the nucleus, which consists of a single neuronal cell type, afferents from the 2 magnocellular cochlear nuclei, and a GABAergic input.

The nucleus magnocellularis projects bilaterally to the nucleus laminaris (Fig. 2; Carr and Konishi, 1988; Takahashi and Konishi, 1988a). Magnocellular axons generally exit at the medial edge of the nucleus magnocellularis, where the parent axon divides in the fiber tract between the nucleus magnocellularis and the medial vestibular nucleus. The ipsilateral branch from each parent axon travels dorsally and then rostrally for several hundred microns in a twisted bundle before giving rise to 3-5 primary collaterals that enter the dorsal surface of the nucleus laminaris (Figs. 2, 3A). This "twisted bundle" increases the path length between the cochlear nucleus and the nucleus laminaris (see also section on conduction velocity, below). The contralateral branch 


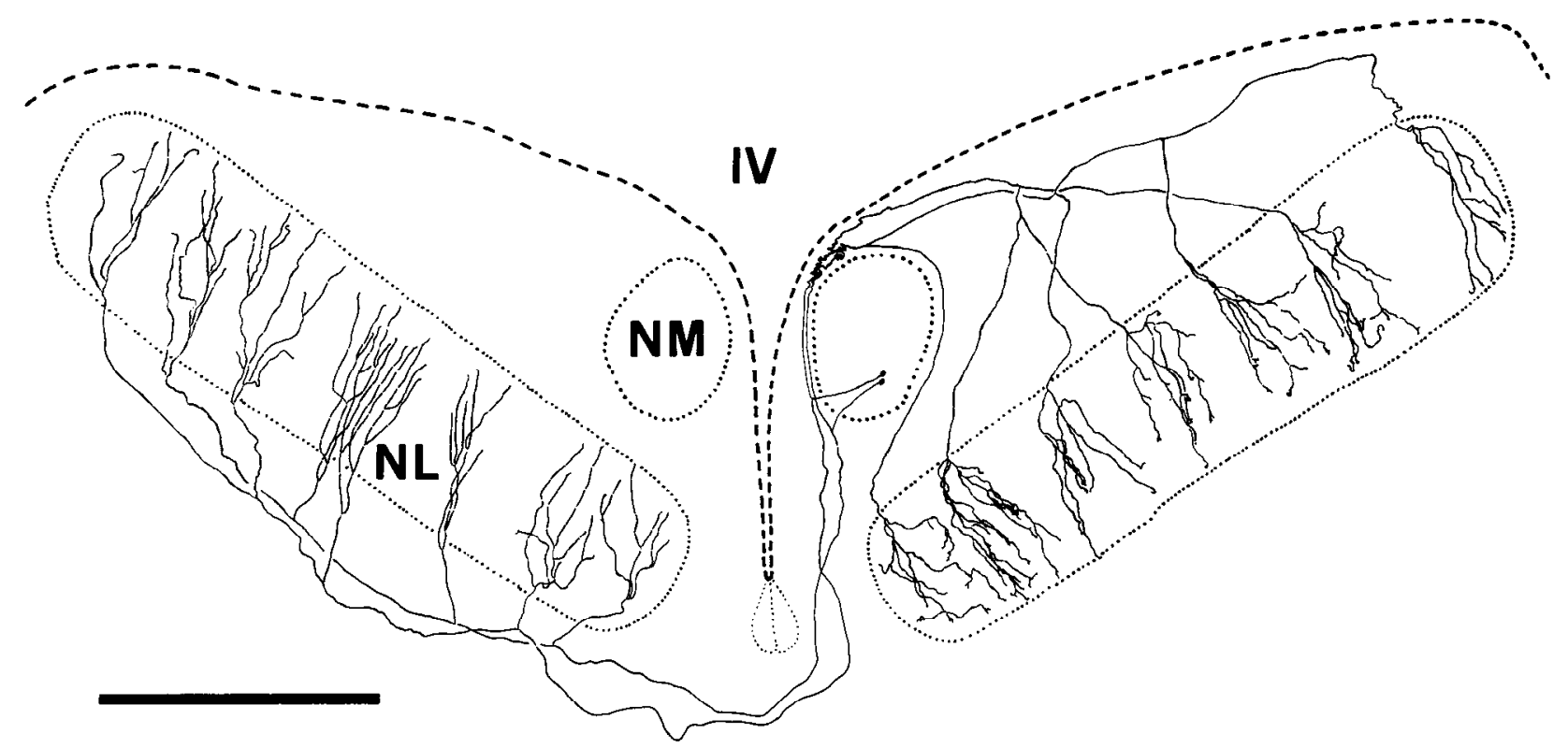

Figure 2. Drawing of transverse section through dorsal brain stem. This drawing shows the projection from the nucleus magnocellularis (NM) to the nucleus laminaris $(N L)$. Two magnocellular neurons were reconstructed from approximately $25-50-\mu \mathrm{m}$ sections with the aid of a camera lucida and superimposed upon a drawing of the dorsal brain stem. These arbors were labeled after a small $\mathrm{HRP}$ injection in the 5.5-kHz region of the nucleus magnocellularis, and each labeled fiber was traced back to a labeled cell body in the injection site. Because each arbor is 3-dimensional (see Fig. $3 A$ ), the actual mediolateral extent of the nucleus laminaris has been exaggerated to accommodate the full arbor. Similarly, each bundle of afferents in the nucleus laminaris forms a cylinder, not a flat sheet, and the "twisted bundle" of ipsilateral axons above the nucleus magnocellularis has been dorsoventrally compressed. IV, fourth ventricle. Scale bar, $1 \mathrm{~mm}$.

crosses the midline and runs rostrally in a diagonal below the ventral border of the contralateral nucleus laminaris, sending primary collaterals into the ventral edge of the nucleus (Fig. 2). The 2 patterns of innervation differ because the ipsilateral collaterals are of similar length and form a fork-shaped arbor, while the contralateral collaterals increase in length along the mediolateral dimension of the nucleus laminaris.

\section{Interdigitation of magnocellular axons within the nucleus laminaris}

Twenty-six magnocellular axons were reconstructed after small HRP injections into the ipsilateral and contralateral $5.5-\mathrm{kHz}$ regions of the nucleus magnocellularis in 2 owls and into the $7-\mathrm{kHz}$ region of a third. Two of these axon arbors are shown in Figure 2. Each ipsi- or contralateral axon gives off primary collaterals that enter the nucleus laminaris at different points along the tonotopic band and interdigitate within the nucleus. All fibers within the nucleus laminaris show a similar branching pattern, though ipsilateral arbors tend to be more exuberant than contralateral arbors (Fig. 2). Most fibers traverse the entire dorsoventral distance of the nucleus laminaris, orthogonal to the borders of the nucleus. At the level of the light microscope, the ipsi- and contralateral axons appear to contact the sparsely distributed laminaris neurons both en passant and as terminal boutons (sce also Fig. 11).

\section{Tonotopic projection to the nucleus laminaris}

The projection from the nucleus magnocellularis to the nucleus laminaris is tonotopically organized (Takahashi and Konishi, 1988a). Magnocellular axons travel above or below the nucleus laminaris until they reach their specific isofrequency band. Then, each axon travels along its isofrequency band in a diagonal that runs from caudomedial to rostrolateral in the nucleus. This tonotopic order is illustrated by a horizontal view of the brainstem, reconstructed from serial sections, which shows the axon trajectories of afferents labeled after HRP injections into the $5.5-$ and $7-\mathrm{kHz}$ regions of the nucleus magnocellularis (Fig. $3 A$ ).

Magnocellular afferents are tuned to a particular frequency (Sullivan and Konishi, 1984) and appear to be matched to their neighbors within the nucleus laminaris. Representative isointensity rate functions from magnocellular afferents within the nucleus laminaris provide a measure of the sharpness of tuning of the afferents (Fig. 3B; cf. Sullivan and Konishi, 1984, their Fig. $16 B$ ). Isointensity rate functions from insi- and contralateral afferents within a single penetration support the observation that the afferents in any dorsoventral array are matched in frequency (Fig. 3,C, D).

The tonotopic organization of the nucleus laminaris was also examined by comparing the position of the recording electrode with the best frequency of the afferent axons in the underlying nucleus laminaris. The approximate position of the electrode was mapped on the surface of the fourth ventricle using a characteristic pattern of blood vessels as a guide. In 17 penetrations, the position of the electrode was well correlated with the best frequency in the underlying nucleus laminaris (Fig. 4).

\section{Response properties of magnocellular afferents}

The cells of the nucleus magnocellularis are primary-like neurons that phase-lock to the auditory stimulus (Sullivan and Konishi, 1984). Figure 5 illustrates the properties of magnocellular neurons. They show characteristic high-frequency bursts of spikes that may be up to 700 spikes/sec during the first 5$20 \mathrm{msec}$ of stimulus onset, followed by tonic firing in response to the sound stimulus (Fig. 5A). The short intervals of the initial burst and the high level of tonic firing may be seen in an interspike-interval histogram (Fig. 5B). An example of phase-locking 

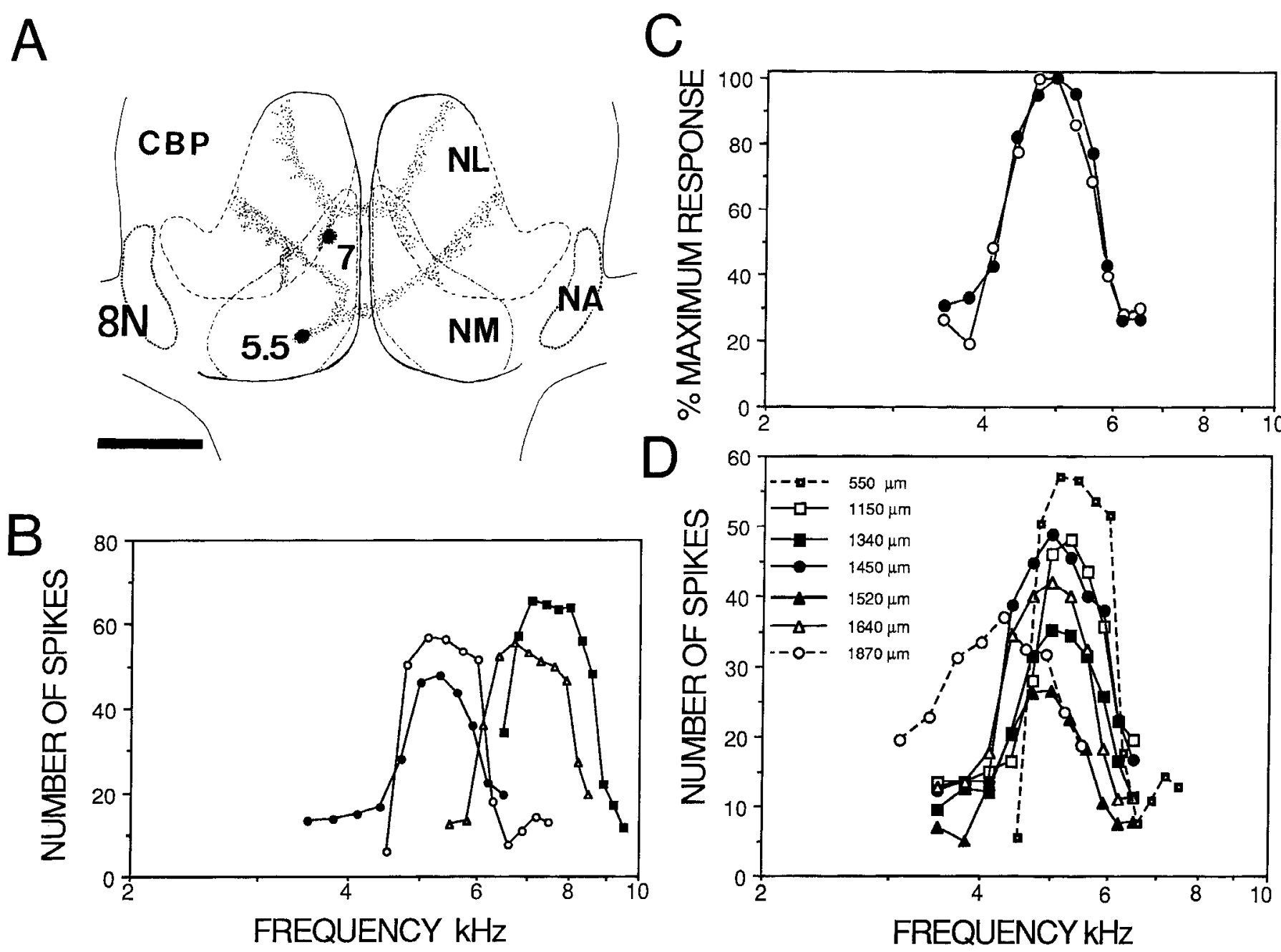

Figure 3. Tonotopic organization of nucleus laminaris. $A$, Horizontal view of the nucleus magnocellularis $(N M)$ and the nucleus laminaris $(N L)$ reconstructed using the midline as fiduciary shows the tonotopic organization of the magnocellular projection to the nucleus laminaris. HRP injections were made into the $5.5-$ or $7-\mathrm{kHz}$ regions of the nucleus magnocellularis in 2 owls. The projections were reconstructed from transverse sections and projected onto a horizontal reconstruction of the brain stem. Note that the rostrolateral portions of the nucleus magnocellularis overlie the medial edge of the nucleus laminaris. NA, nucleus angularis; CBP, cerebellar peduncle; $8 \mathrm{~N}$, eighth nerve. Scale bar, $1.5 \mathrm{~mm}$. $B$, Isointensity rate functions, taken at $30 \mathrm{~dB}$ above threshold and measured from ipsilateral (open symbols) and contralateral (solid symbols) magnocellular afferents recorded in the nucleus laminaris, resemble the tuning curves obtained by Sullivan and Konishi (1984). $C$, Isointensity rate functions from ipsiand contralateral magnocellular afferents recorded in the same penetration in the nucleus laminaris show that inputs from the 2 sides are matched in frequency. The ipsilateral response (open symbols) was recorded at a depth of $1320 \mu \mathrm{m}$. The contralateral response (solid symbols) was recorded at a depth of $1400 \mu \mathrm{m}$. Each function was normalized to the maximum response. $D$, Isointensity rate functions from magnocellular afferents recorded in a single penetration through the nucleus laminaris. Ipsilateral afferents are shown as open symbols, and contralateral afferents as solid symbols. Rate functions from afferents recorded on the dorsal or ventral borders of the nucleus are shown as dashed lines. The depth at which each afferent was penetrated is indicated on the plot. Note that the afferents within the nucleus were matched in frequency, while 2 units recorded on the borders of the nucleus (dashed lines) were not.

in a magnocellular neuron may be seen in the period histogram in Figure $5 C$. Phase-locking has been found up to $9 \mathrm{kHz}$ using extracellular techniques (Sullivan and Konishi, 1984). Results from those recordings and the present intracellular study are compared in Figure 5D. The vector-strength values from 485 intracellular recordings from magnocellular axons were plotted as a function of best frequency. A decrease in the degree of phaselocking was observed with increasing stimulus frequency, as indicated by the regression line in Figure $5 D$. Figure $5 D$ also includes a regression line calculated from extracellular records in Figure 2 of Sullivan and Konishi (1984). The 2 regression lines had similar slopes, indicating that the vector-strength values showed similar decreases with increasing best frequency but had different intercepts.

\section{Physiological recordings reflecting the anatomy of the auditory} brain stem

In order to demonstrate the change in conduction delay in magnocellular axons, the nucleus laminaris was penetrated perpendicular to its dorsal and ventral surfaces and parallel to the incoming axons. Sampling of axons during each penetration was therefore confined to a single bundle of afferents having the same or similar best frequency. Best frequencies were determined for all afferents. In preliminary experiments designed to determine the correct head and electrode angles, we observed that, if the nucleus laminaris was not penetrated parallel to the magnocellularis afferents, a systematic change in best frequency was observed with depth. 


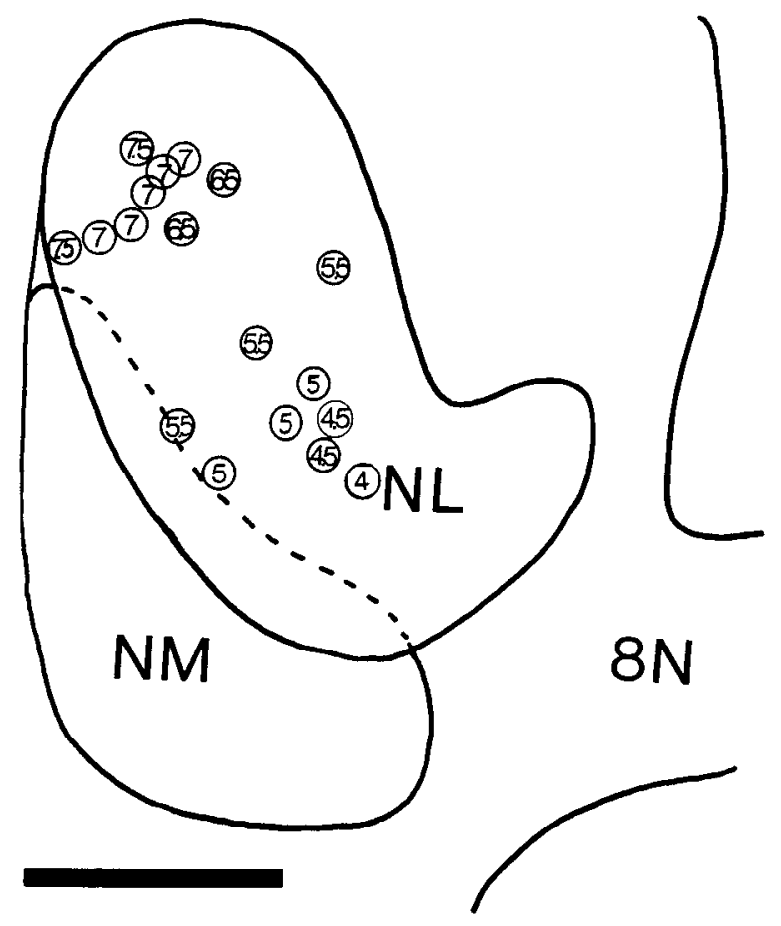

Figure 4. The approximate location of 17 penetrations through nucleus laminaris plotted on same horizontal view as Figure $3 \mathrm{~A}$. In 5 experiments, the location of each penetration was marked on a drawing of the floor of the fourth ventricle, using the distinctive pattern of blood vessels as a guide. These electrode locations were normalized with respect to the anterior-posterior axis of the nucleus. Scale bar, $1.5 \mathrm{~mm}$. $\mathrm{NL}$, nucleus laminaris; $\mathrm{NM}$, nucleus magnocellularis; $8 \mathrm{~N}$, eighth nerve.

In each penetration, recordings reflected the anatomy of the auditory brain stem. After the electrode penetrated the dorsal surface of the brain stem, eighth-nerve fibers on their way to the nucleus magnocellularis were encountered in the first 100$200 \mu \mathrm{m}$. These large axons were characterized by overshooting action potentials and high best frequencies $(6-9 \mathrm{kHz})$. Next encountered were ipsilateral axons from the nucleus magnocellularis with varying best frequency. Within $100-200 \mu \mathrm{m}$ of the dorsal border of the nucleus laminaris, the variability in best frequency diminished (see Fig. $3 D$ ). This change corresponds to the region where axons enter their best-frequency band and send primary collaterals into the nucleus laminaris (Fig. 2). The dorsal border of the nucleus laminaris varies between 600-1000 $\mu \mathrm{m}$ from the floor of the fourth ventricle. The depth is greatest in the caudal and medial portions of the nucleus laminaris that lie ventral to the nucleus magnocellularis and is least in the most lateral portions of the nucleus. The dorsal border of the nucleus laminaris could be recognized both by the first recordings from contralateral afferents and by depth. Figure 6 shows a penetration where an HRP-containing electrode followed the track of the previous intracellular recording (best frequency, $5.5 \mathrm{kHz}$ ). A small amount of HRP was injected at the depth at which the first contralateral afferent was recorded $(800 \mu \mathrm{m})$, and the second injection was made at a depth of $1500 \mu \mathrm{m}$. Two small injection sites can be seen at the dorsal and ventral surfaces of the nucleus laminaris. They appear interconnected because labeled afferents that picked up the HRP span the distance between them. The ventral surface of the nucleus laminaris could be recognized both by depth and because responses to stimulation of the ip- silateral ear could no longer be obtained. Similar HRP injections were made in most of the owls used for neurophysiological recordings, and in all cases, the label was localized to the dorsal and ventral borders of the nucleus.

\section{Afferent axons showing changes in delay with depth in the nucleus laminaris}

Within the nucleus laminaris, we recorded from ipsilateral and contralateral afferents. Their phase-locking properties allowed us to measure changes in the mean phase of period histograms obtained within a bundle of afferents during a single electrode penetration through the nucleus laminaris. The mean phase represents the mean arrival time of phase-locked spikes relative to the beginning of tonal periods (e.g., see Fig. 5C). Changes in the mean phase indicate changes in the mean arrival time of phase-locked spikes.

In each penetration, we observed monotonic changes of mean phase from afferents from either the ipsilateral or contralateral cochlear nucleus (Fig. 7). In penetrations through regions of the nucleus laminaris with low best frequency, these phase changes could occur within a single stimulus cycle (Fig. $7, A, B$ ). In regions of higher best frequency, we found monotonic changes in mean phase interrupted by sudden shifts of phase angle between $360^{\circ}$ and $0^{\circ}$ (see Fig. $7 C$, dashed lines). We made the assumption that these monotonic changes in phase with depth occurred within a single stimulus cycle, while the sudden shifts in phase angle $(\theta)$ were due to the cyclic nature of phase or "wraparound," as shown in Figure $7 \mathrm{C}$. The period length of the stimulating tone becomes shorter as the frequency increases, and therefore a best frequency exists where the delay mapped in the nucleus is longer than the stimulus period, as shown in Figure $7 C$. Phase unwrapping was required in the many penetrations within the nucleus laminaris in which we recorded neurons with periods shorter than twice the maximum delay or where the first neuron in a penetration had a mean phase other than $0 / 360^{\circ}$.

In 13 owls, we measured the mean phase angle from 419 intracellular recordings of afferents within the nucleus laminaris (Table 1). Twenty-five penetrations were made through the nucleus laminaris, from 8 different tonotopic bands with best frequencies from 4.0 to $7.5 \mathrm{kHz}$. Figure $8 A$ shows representative changes in peak phase with depth from both ipsi- and contralateral axons recorded in single penetrations through the nucleus laminaris, and Figure $8 B$ plots all the data obtained for each frequency. Ipsi- and contralateral responses have been segregated for the sake of clarity in Figure $8 B$. In all cases, the mean phase recorded from afferents from either side varied with recording depth. As an intracellular electrode passed through the dorsoventral extent of the nucleus laminaris, both ipsi- and contralateral fibers of the same best frequency were encountered with equal probability. The mean phase of the ipsilateral recordings increased with depth, while that of the contralateral units decreased. Once the dorsal or ventral borders of the nucleus were reached, the phase shifts were no longer ordered, and the best frequency was no longer constant. This follows from the anatomy because the border not only contained fibers entering that part of the nucleus laminaris, but also fibers that were passing through to more distant regions.

Delays of phase-locked spikes varied systematically with depth for all frequencies tested, with the result that similar time delays, measured in $\mu \mathrm{sec}$, were found for all frequencies. We sampled neurons tuned to frequencies between $4-7.5 \mathrm{kHz}$ and found that the slopes (see Table 1 and regression lines drawn through the 


\section{A}

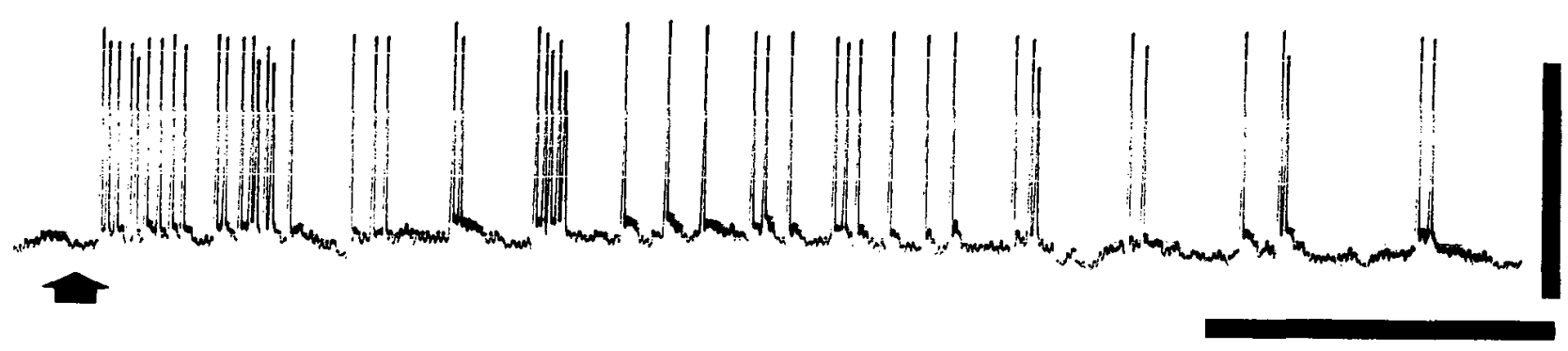

B
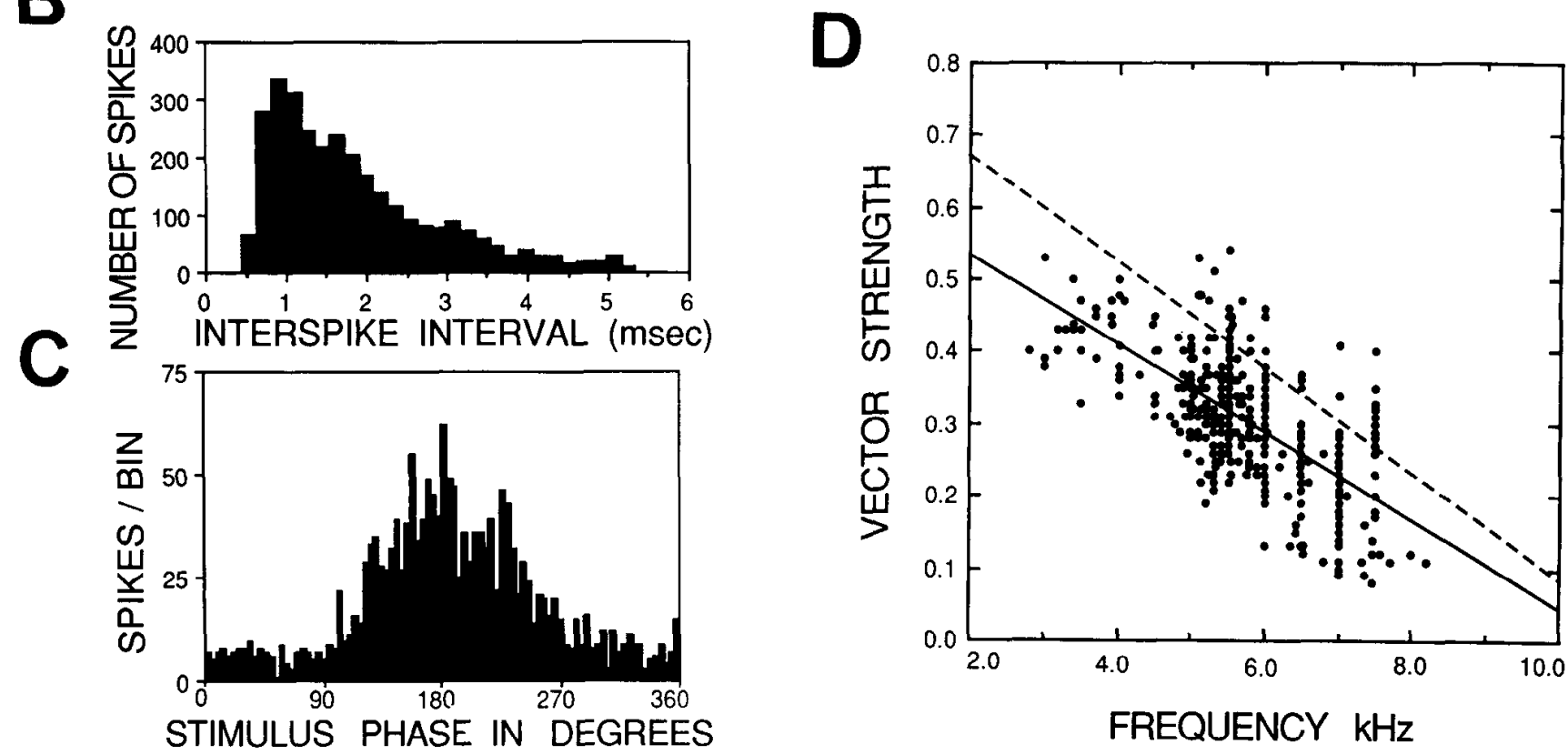

Figure 5. Examples of response properties of magnocellular neurons. A, Intracellular response of a contralateral magnocellularis axon recorded in the nucleus laminaris to a $100-\mathrm{msec}$ tone burst at $5502 \mathrm{kHz}$. Note the initial burst of spikes in response to the stimulus (arrow). The spikes are characteristic of axon recordings and show a rapid repolarization and no after hyperpolarization. Scale bars, $25 \mathrm{msec}, 50 \mathrm{mV}$. $B$, Interspike interval histogram for an ipsilateral afferent recorded in the nucleus laminaris in response to a tonal stimulus of $5532 \mathrm{~Hz}$. This unit had a latency of 2.9 msec, vector strength of 0.21 , and mean phase of $175^{\circ}$. Each histogram was computed from the first 64 msec of 100 stimuli of 100 -msec duration. $C$, Period histogram computed for a magnocellular neuron with a best frequency of $4500 \mathrm{~Hz}$ contains 1698 spikes and has a mean phase of $187^{\circ}$ and a vector strength of 0.47 . D. Vector strength as a function of best frequency for 485 of the magnocellular afferents recorded in this study. The regression line has a slope of -0.061 and a $y$-intercept of 0.64 . A similar regression (dashed line), calculated from extracellular recordings in the nucleus magnocellularis, has a slope of -0.074 and a $y$-intercept of 0.83 (calculated from Sullivan and Konishi, 1984, their Fig. 2).

points in Fig. $8 A$ ) become progressively steeper as the period of the stimulating frequency decreases. If phase is converted to time, as has been done for the right-hand $y$-axes of Figure 8, it may be seen that the same range of delays occurs over roughly the same depth for all frequencies (Table 1). Conduction delays in $\mu \mathrm{sec}$ were calculated from the slope of each plot over the 700$\mu \mathrm{m}$ depth of the nucleus laminaris for penetrations in the 4-7.5 $\mathrm{kHz}$ region (Table 1). Delays over the $700-\mu \mathrm{m}$ depth of the nucleus laminaris were about $170 \mu \mathrm{sec}$ for the ipsilateral path (mean delay $=167, \mathrm{SD}=28 \mu \mathrm{sec}, n=25$ penetrations) and $160 \mu \mathrm{sec}$ for the contralatcral path (mean delay $=157$, SD $34 \mu \mathrm{sec}, n=25$ ).

Similarity of conduction time through the nucleus laminaris to measured delays

We estimated the conduction time between the dorsal and ventral borders of the nucleus laminaris in order to support our assumption that the sudden phase shifts observed did not involve multiple periods. The conduction time from the ear to either the dorsal or ventral borders of the nucleus laminaris was measured in 8 penetrations in 2 owls. The difference in latency between the borders was equal to the conduction time through the nucleus.

Latency was measured by plotting shifts in the mean phase of the response of magnocellular neurons to changes in stimulus frequency (Fig. 9A; Anderson et al., 1970; Yin and Kuwada, 1983 ). Figure $9 B$ shows plots of mean response phase as a function of stimulus frequency for 8 different magnocellular afferents chosen to represent a range of frequencies and latencies. Because latencies vary with frequency, most measurements of latency were made from units recorded in 5 penetrations through the central portion of the $5.5-\mathrm{kHz}$ region of the nucleus laminaris (Fig. 9C). Latencies were measured for both ipsi- and contralateral fibers from either the dorsal or ventral portions of the 

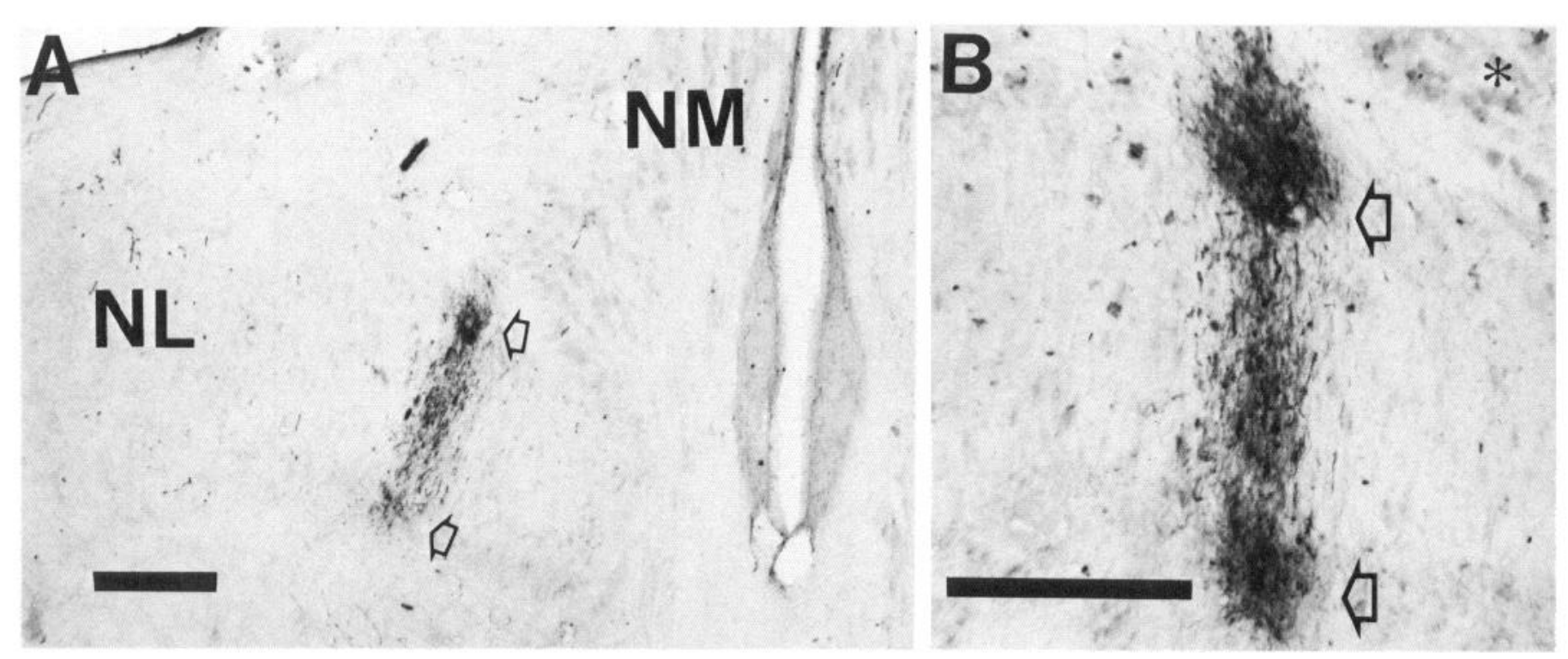

Figure 6. Penetration with HRP-containing electrode. The electrode followed the track of the previous intracellular recording with a best frequency of $5.5 \mathrm{kHz}$. A, A small amount of HRP was injected at $800 \mu \mathrm{m}$, the depth at which the first contralateral afferent was recorded (top arrow), while the second injection was placed at a depth of $1500 \mu \mathrm{m}$ (bottom arrow). Some edema has resulted in swelling of the region over the nucleus magnocellularis. Scale bar, $400 \mu \mathrm{m}$. NL, nucleus laminaris; NM, nucleus magnocellularis. $B$, The 2 injection sites (arrows) may be seen at the dorsal and ventral borders of the nucleus laminaris in the adjacent section. Asterisk marks the nucleus magnocellularis cells. Scale bar, $400 \mu \mathrm{m}$.

nucleus. For ipsilateral fibers, the mean latency to the dorsal border of the nucleus was $2.82 \mathrm{msec}(\mathrm{SD}=0.24, n=16)$ and to the ventral border, $3.02 \mathrm{msec}( \pm 0.23, n=8)$, giving a mean conduction time through the nucleus of $200 \mu \mathrm{sec}$. The latency of the contralateral fibers was $2.87 \mathrm{msec}( \pm 0.21, n=11)$ to the ventral border and $3.06 \mathrm{msec}( \pm 0.21, n=10)$ to the dorsal border, with a mean conduction time of $190 \mu \mathrm{sec}$. Thus, the mean latency between the dorsal and ventral borders of the nucleus differed by about $200 \mu \mathrm{sec}$. The latencies between dorsal and ventral borders were significantly different in both cases. Student's $t$ tests between the iD and iV means and between the $\mathrm{cV}$ and the $\mathrm{cD}$ (see Fig. 9C) means showed both were significantly different at $p<0.05$. Neither the $\mathrm{iD}$ and $\mathrm{cV}$ means nor the $\mathrm{iV}$ and $\mathrm{cD}$ means were significantly different (Student's $t$ test; Fig. 9C). The latencies were also in agreement with the measures of delay (about $160 \mu \mathrm{sec}$ ) obtained in the previous section. A large variability in latency was observed (Fig. $9 C$; note SDs of about $200 \mu \mathrm{sec}$ ). This variability was not due to pooling the data from several penetrations, because neighboring axons could differ in latency by as much as $200 \mu \mathrm{sec}$.

Ipsilateral and contralateral afferents took about the same time to reach the borders of the nucleus (Fig. $9 \mathrm{C}$ ). There is a difference of about $1 \mathrm{~mm}$ in path length from the ipsi- and contralateral cochlear nuclei to the borders of the nucleus laminaris, with a mean ipsilateral path length of $2.3 \mathrm{~mm}( \pm 0.4, n$ $=8)$ and a mean contralateral length of $3.2 \mathrm{~mm}( \pm 0.8, n=9)$. The reason for the increase in SD for contralateral lengths may be seen in Figure 2; contralateral fibers show a mediolateral increase in path length that, when pooled, yields a large SD. The difference in path length between ipsilateral and contralateral afferents may be partly compensated for because ipsilateral fibers were smaller than contralateral fibers. Approximate measures of axon diameters were obtained from HRP-filled fibers. With no correction made for tissue shrinkage, ipsilateral axon diameters were about $1.4 \mu \mathrm{m}(\mathrm{SD}=0.4, n=54)$, and contralateral diameters were about $2.4 \mu \mathrm{m}(\mathrm{SD}=0.7, n=44)$.

\section{Short internodes may reduce conduction velocity in magnocellular afferents}

Conduction velocity in the afferents within the nucleus laminaris was calculated to be between 3 and $5 \mathrm{~m} / \mathrm{sec}$ from both latency (Fig. 9) and delay (Fig. 8) data. These low velocities may be caused by the short internodal distances found in afferent fibers within the nucleus laminaris (Fig. 10). Nodes could be readily distinguished at the light microscopic level, in the same HRPlabeled fibers shown in Figures 2 and $4 B$, as narrowings in fiber diameter (Fig. 10,B, C). When those internodal segments confined to a single tissue section were measured, it was found that nodes within the nucleus laminaris are both more numerous and more regularly spaced (mean $=58 \mu \mathrm{m}, \mathrm{SD}=12, n=60$ ) than nodes in the axons in the fiber bundles above and below the nucleus (mean $=334 \mu \mathrm{m}, \mathrm{SD}=60, n=20$ ). Nodes in ipsilateral axons close to the dorsal border of the nucleus laminaris were also short (mean $=185 \mu \mathrm{m}, \mathrm{SD}=46, n=13$; Fig. $10 A)$.

\section{Magnocellular afferents converging on laminaris neurons}

Laminaris neurons receive large numbers of terminals from both the ipsilateral and contralateral nucleus magnocellularis (C. E. Carr, unpublished observations; Fig. 11A). These neurons have large oval cell bodies $(30-\mu \mathrm{m}$ long diameter) with very short dendrites (Fig. $11 B$ ). With this morphology, it is unlikely that the dendrites are electrotonically separate from the soma. Laminaris neurons were rarely penetrated in this study. The reason may be that these neurons occupy a small portion of the total volume of the nucleus. The somata are distributed sparsely throughout the nucleus (see Fig. 1), and the dendrites are short. It is likely that all recordings were made from laminaris axons, because only 1 neuron was encountered that had a best frequency similar to the neighboring magnocellular afferents. The axons of laminaris neurons travel through the nucleus to the rostrolateral exit of the efferent tract, and it is reasonable to assume 
Table 1. Estimated conduction time between the dorsal and ventral surfaces of the nucleus laminaris

\begin{tabular}{llcllll}
$\begin{array}{l}\text { Fre- } \\
\text { quency } \\
(\mathrm{kHz})\end{array}$ & $N$ & $\begin{array}{l}\text { Number } \\
\text { of units } \\
(\mathrm{I}+\mathrm{C})\end{array}$ & $\begin{array}{l}\text { Ipsi- } \\
\text { lateral } \\
\text { delay } \\
(\% \mu \mathrm{m})\end{array}$ & $\begin{array}{l}\text { Mean } \\
\text { delay } \\
(\mu \mathrm{sec} / \\
700 \mu \mathrm{m})\end{array}$ & $\begin{array}{l}\text { Contra- } \\
\text { lateral } \\
\text { delay } \\
(\% \mu \mathrm{m})\end{array}$ & $\begin{array}{l}\text { Mean } \\
\text { delay } \\
(\mu \mathrm{sec} / \\
700 \mu \mathrm{m})\end{array}$ \\
\hline 4 & 1 & 21 & 0.31 & 149 & 0.36 & 177 \\
4.5 & 1 & 14 & 0.41 & 159 & 0.39 & 157 \\
5 & 3 & 36 & 0.41 & 158 & 0.46 & 179 \\
5.5 & 8 & 113 & 0.49 & 175 & 0.46 & 159 \\
6 & 4 & 58 & 0.55 & 183 & 0.41 & 134 \\
6.5 & 2 & 27 & 0.51 & 152 & 0.58 & 175 \\
7 & 4 & 105 & 0.58 & 160 & 0.58 & 162 \\
7.5 & 2 & 45 & 0.69 & 178 & 0.63 & 162 \\
\hline
\end{tabular}

Estimated conduction time does not change with frequency for both ipsi- and contralateral afferents. For each stimulus frequency used, we show the number of penetrations $(N)$, the number of units [both ipsi- (I) and contralateral (C)] in all penetrations, the mean change in phase with depth for both ipsi- and contralateral afferents, and the mean delay over $700 \mu \mathrm{m}$.

that the axons with different best frequencies originate from distant points. In addition, the action potentials recorded had fast-rising spikes with no obvious postsynaptic potentials (see Fig. 16).

\section{Laminaris neuron response to interaural time differences}

Physiological results were obtained from 28 laminaris neurons that were sensitive to ITD. In 16 cases, we held the neuron only long enough to measure its response to interaural delays. In the remaining 12 cases, we were able to measure monaural and binaural phase-locking responses to tonal stimuli (Table 2). Within this set of 12 neurons, we calculated interspike interval histograms in 10 cases and obtained isointensity rate functions for 3 neurons. We present the data on the frequency responses, despite the small sample sizes, because such data were difficult to obtain.

Selectivity to ITD was found in laminaris neurons tuned to best frequencies that ranged from 1 to $7 \mathrm{kHz}$. Figure 12 shows the responses of 4 laminaris neurons with different best frequencies and plots the number of spikes evoked as a function of the interaural delay of a tone at or close to each neuron's best frequency. The response of laminaris neurons varied in a cyclic manner with the ITD of a sound stimulus, and the period of the ITD response function matched that of the stimulus tone. Because all the response peaks in each plot were of similar height and were evoked by the same interaural phase difference, these neurons may be said to show phase ambiguity (Takahashi and Konishi, 1986).

\section{Monaural and binaural phase sensitivity in laminaris neurons}

Laminaris neurons phase-locked to the auditory stimulus and were driven by both monaural and binaural stimuli (Figs. 13, 14). The period histograms in these figures show phase-locked responses to stimulation of the contralateral and ipsilateral ears. Figure 13 reflects the observed pattern of activity. Comparison of the ipsi- and contralateral period histograms showed a difference in mean phase of about $44^{\circ}$ or $28 \mu \mathrm{sec}$ (ipsilateral leading contralateral). It may be seen from the interaural delay curve obtained for the same neuron that a peak ocurred at $-30 \mu \mathrm{sec}$ (Fig. 13D). Therefore, if the contralateral ear was stimulated 30 $\mu \mathrm{sec}$ before the ipsilateral ear, the 2 peaks of the period histo-
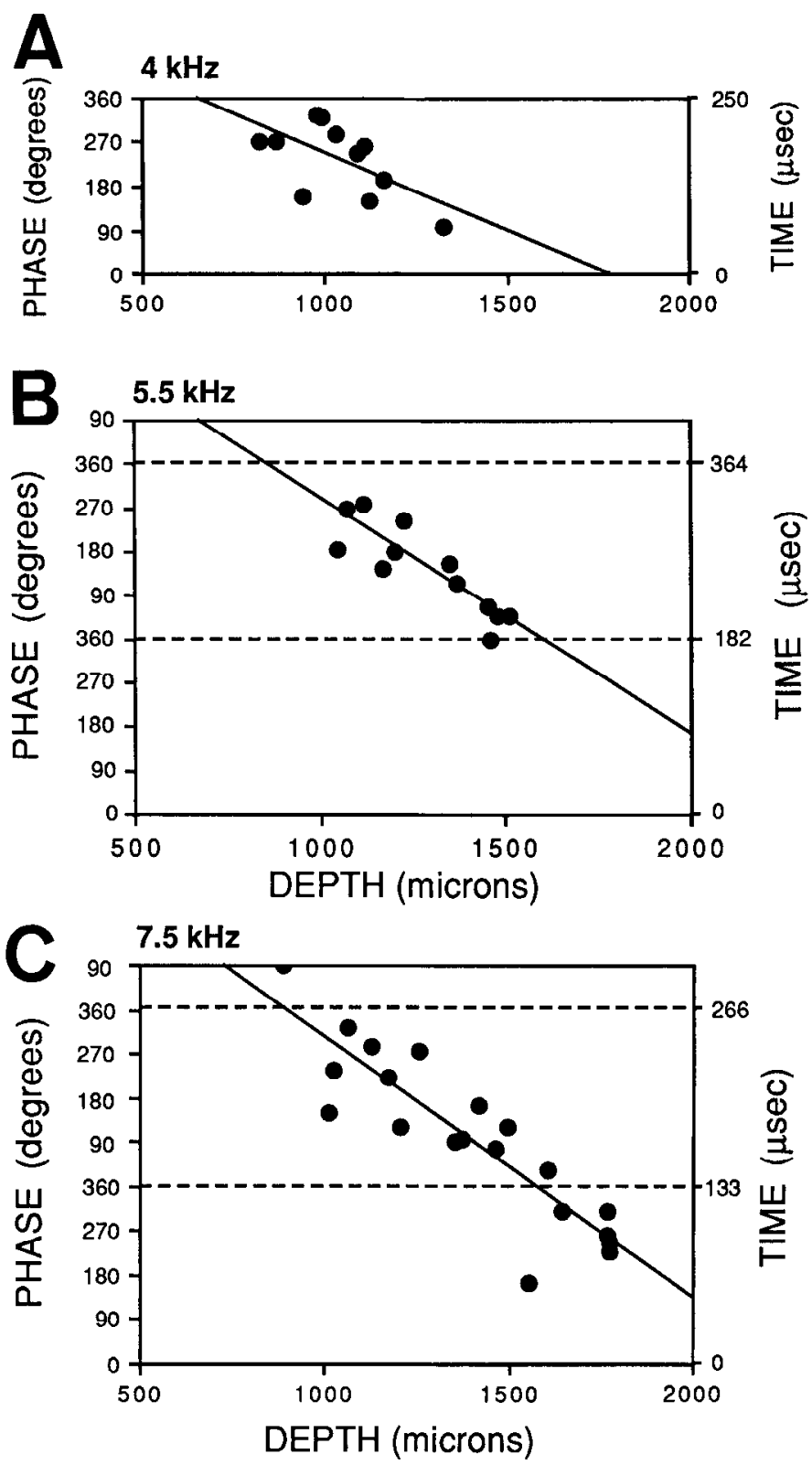

Figure 7. Mean phase angles of contralateral fibers recorded at different depths during 3 penetrations through different best-frequency regions of nucleus laminaris. These penetrations were chosen because the first measurements of mean phase at the dorsal surface of the nucleus laminaris began around $360^{\circ}$, in order to show that wraparound occurs when the delay mapped is larger than the stimulus period. These data, plus the recordings from ipsilateral fibers obtained from the same penetration, are also plotted in Figure $8 A$. $A$, In the $4-\mathrm{kHz}$ region of the nucleus laminaris (period $=250 \mu \mathrm{sec}$ ), regular changes in phase were observed within a single stimulus cycle. $B$, Regular changes in phase were also observed within a single stimulus cycle in the $5.5-\mathrm{kHz}$ region (period $=182 \mu \mathrm{sec}$ ). Neighboring stimulus cycles are plotted (dotted lines) for comparison with $C$. $C$, In the $7-\mathrm{kHz}$ region of the nucleus laminaris, monotonic changes in mean phase were interrupted by sudden shifts of mean phase. These shifts were interpreted as a wraparound to the next stimulus cycle (dashed lines).

grams coincided. The result of binaural stimulation at a favorable phase difference is shown below the monaural period histograms in Figure 13C. When the 2 monaural peaks coincided at a favorable ITD, there was a large binaural response.

Figure 14 shows a laminaris neuron stimulated with a fre- 

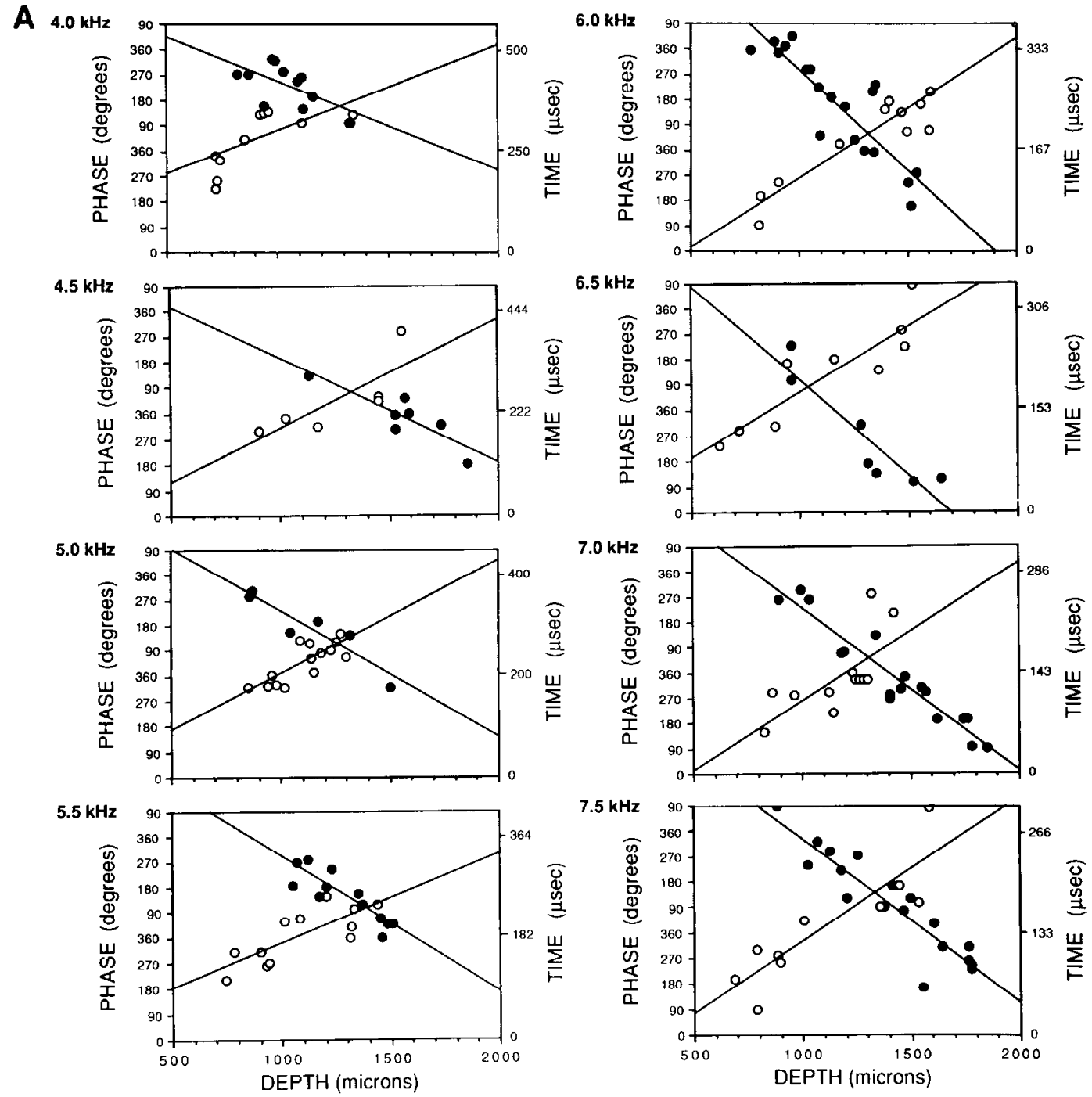

quency of $1025 \mathrm{~Hz}$. This neuron had the lowest best frequency encountered in this study. Its preferred interaural delay appeared to be greater than $300 \mu \mathrm{sec}$. Although these delays were greater than the physiological range (200-220 $\mu \mathrm{sec})$ available to the owl at higher frequencies (Moiseff, 1989), they could be produced by the interaural canal at low frequencies (Calford and Piddington, 1988). Comparison of the ipsi- and contralateral period histograms in Figure $14, A$ and $B$, shows a difference of about $165^{\circ}$ or $-447 \mu \mathrm{sec}$ (contralateral leading ipsilateral). It may be seen from the interaural delay curve obtained for the same neuron that a peak occurs at an ITD greater than $-300 \mu \mathrm{sec}$ (Fig. $14 E$ ). The result of binaural stimulation at both favorable and unfavorable phase differences may be seen below the monaural period histograms. A large binaural response was observed when the 2 monaural peaks overlapped at a favorable ITD $(-150$ $\mu \mathrm{sec}$ ), while stimulation at an ITD of $+100 \mu \mathrm{sec}$ yielded a response with low vector strength and below the monaural level (Fig. 14,C, D).

We were able to predict ITD from analysis of the monaural phase responses (Table 2). Phase differences between the 2 ears are generally such that, to bring peaks into coincidence, the stimulus to the ipsilateral ear must be delayed with respect to the contralateral ear. This "predicted ITD" is shown in Table 2 and compared with the "observed ITD" obtained from the ITD curves. The mean ITD (Takahashi and Konishi, 1986) was calculated as follows:

$$
\text { Mean ITD }=\sum_{i=1}^{n} R_{i} \times \mathrm{ITD}_{i} / \sum_{i=1}^{n} R_{i}
$$

where $R_{i}$ is the spike number at the $i$ th ITD, and $n$ is the number of sample ITDs for the peak closest to predicted peak for each neuron. Observed and predicted peaks generally did not differ by more than $40 \mu \mathrm{sec}$ and were generally centered around and contralateral to 0 ITD, between +10 and $-150 \mu \mathrm{sec}$, that is, in the contralateral sound field (Fig. 15).

Figures 12-15 and Table 2 illustrate the range of responses to interaural delays. An important observation is that the response to the least-favorable delays drops well below the level of the monaural responses, though not below the low level of spontaneous activity. In general, monaural stimulation evoked about 50\% fewer spikes than the best binaural delay. Responses were generally slightly stronger for the stimulation of the ipsi- 

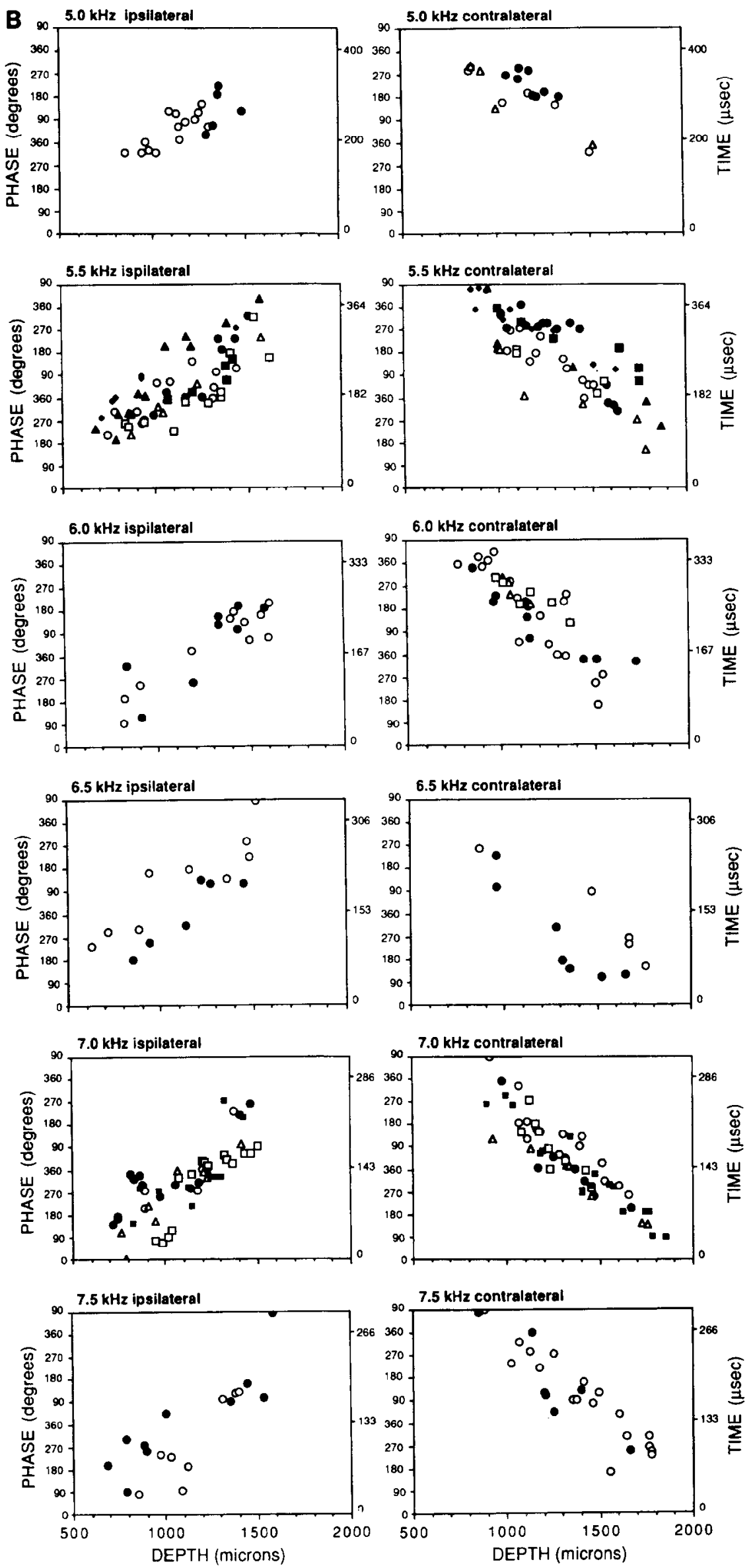

Figure 8. Systematic changes in mean phase along dorsoventral axis of nucleus laminaris. $A$, Representative single penetrations through the $4-7.5-\mathrm{kHz}$ regions of the nucleus laminaris. The stimulating frequency for each penetration is indicated at the top left of each plot, and the $x$-axis shows recording depth within the nucleus laminaris as measured from the floor of the fourth ventricle. The double $y$-axis shows phase in degrees on the left and in $\mu \mathrm{sec}$ on the right. Because the data were measured in degrees, it should be noted that the relative phases of each plot may be shifted arbitrarily by multiples of $2 \pi$. Solid circles represent the mean phase of afferent axons from the contralateral nucleus magnocellularis, and open circles represent recordings from ipsilateral afferents. Regression lines were drawn for both the ipsi- and contralateral afferents. All regression lines had correlation coefficients $\left(r^{2}\right)$ greater than 0.75 . $B$, Plots of all penetrations through the $5-7.5-\mathrm{kHz}$ regions of the nucleus laminaris. Unlike $A$, responses from ipsilateral and contralateral afferents have been separated. Each symbol type represents a different penetration through the nucleus laminaris. The axes are the same as those in $A$. 
A
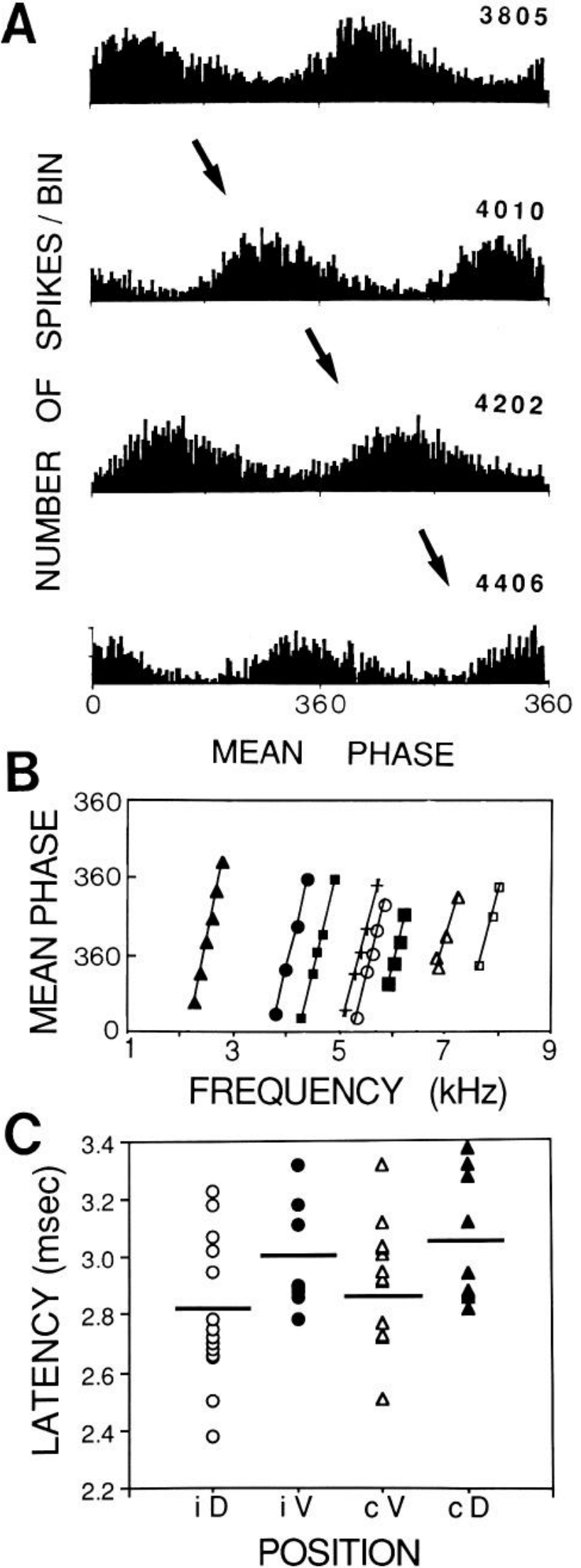

Figure 9. Differences in conduction time between ear and dorsal and ventral borders of nucleus laminaris may be measured from phasefrequency plots. $A$, Period histograms from ipsilateral magnocellular afferent 351150 at 4 different stimulus frequencies $(3805,4010,4202$, $4406 \mathrm{~Hz}$ ) show a regular shift in response phase with frequency (arrows). $B$, Plots of mean phase as a function of stimulus frequency for 8 different magnocellular afferents, including 351150 (solid circles). The slope of
A
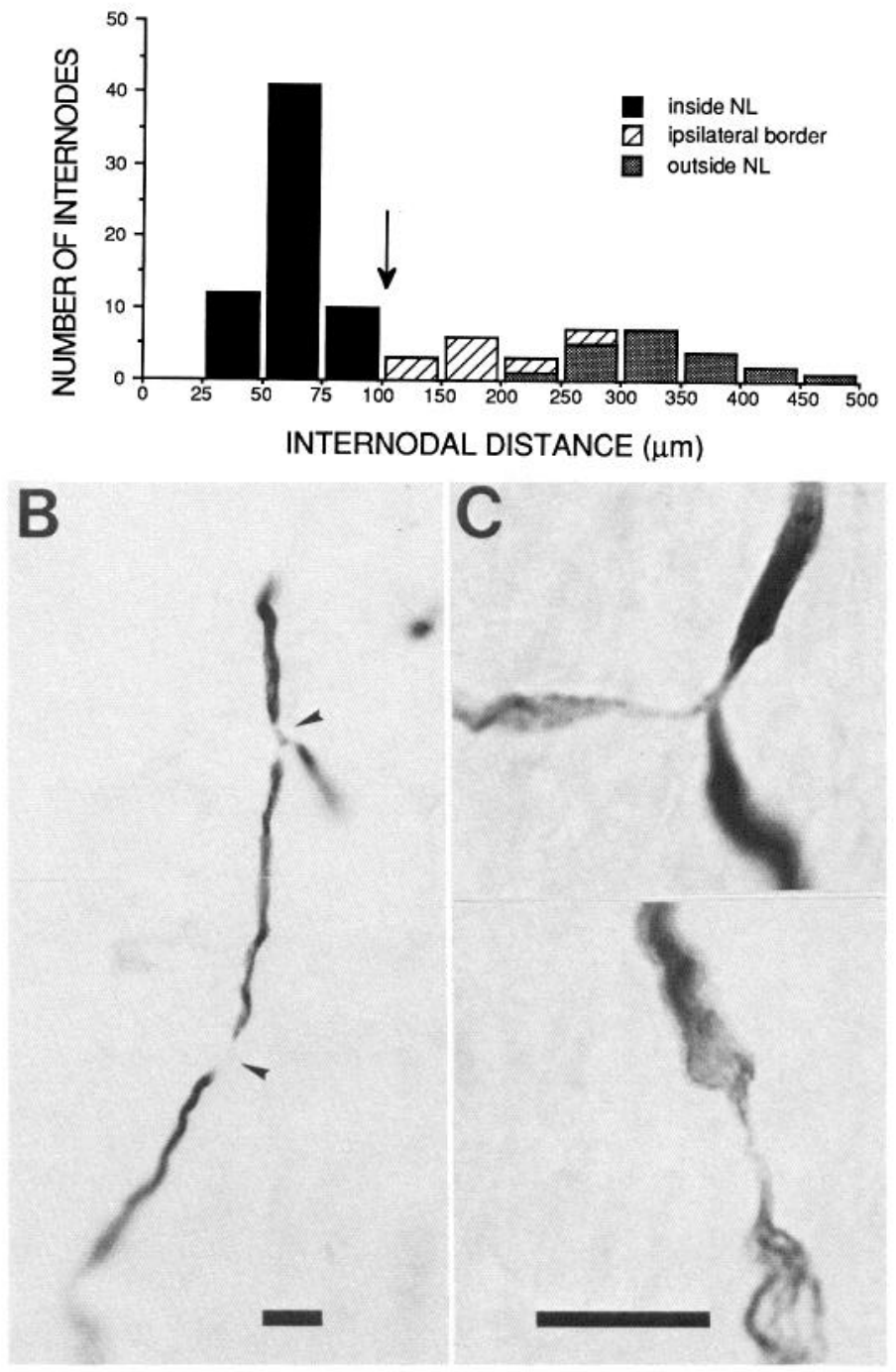

Figure 10. Nodes in magnocellular axons. A, Bar graph shows that the nodes within the nucleus laminaris are both more numerous and more regularly spaced than nodes in the axons in the fiber bundles above and below the nucleus. The ipsilateral axons close to the dorsal borders of the nucleus laminaris also have short internodes. The arrow indicates a change in bar size from 25 to $50 \mu \mathrm{m}$. B. Montage of a single fiber shows nodes at an axon branch and in an axon segment (arrowheads). The nodes are distributed at approximately $50 \mu \mathrm{m}$ intervals. Scale bar, $10 \mu \mathrm{m}$. $C$, High-magnification photomicrographs of the nodes at branch points and axon segments show that they may be readily distinguished as narrowings in HRP-labeled fibers. Scale bar, $10 \mu \mathrm{m}$.

each plot is equal to the latency of the unit's response to the stimulus. These afferents were chosen to represent a range of frequencies and latencies. Unit 350110 (solid triangles) had a latency of $3.6 \mathrm{msec}, 351150$ (solid circles), $2.9 \mathrm{msec}$; contralateral unit 350104 (small solid squares), $3 \mathrm{msec}$; contralateral unit 351222 (crosses), $2.7 \mathrm{msec}$; ipsilateral unit 351237 (open circles), $2.9 \mathrm{msec}$; ipsilateral unit 351033 (large solid squares), $2.7 \mathrm{msec}$; contralateral unit 350174 (open triangles), $2.6 \mathrm{msec}$; and ipsilateral unit 351171 (open squares), $2.6 \mathrm{msec}$. All regression lines had correlation coefficients greater than 0.98 . $C$, Plot of latencies from 5 penetrations through the nucleus laminaris. Latencies of ipsilateral $(i)$ and contralateral $(c)$ axons measured at the dorsal border of the nucleus are in columns marked $i D$ and $c D$, respectively, and latencies measured at the ventral border are marked $i V$ and $c V$. The positions of the mean of each column are indicated by a bar. 

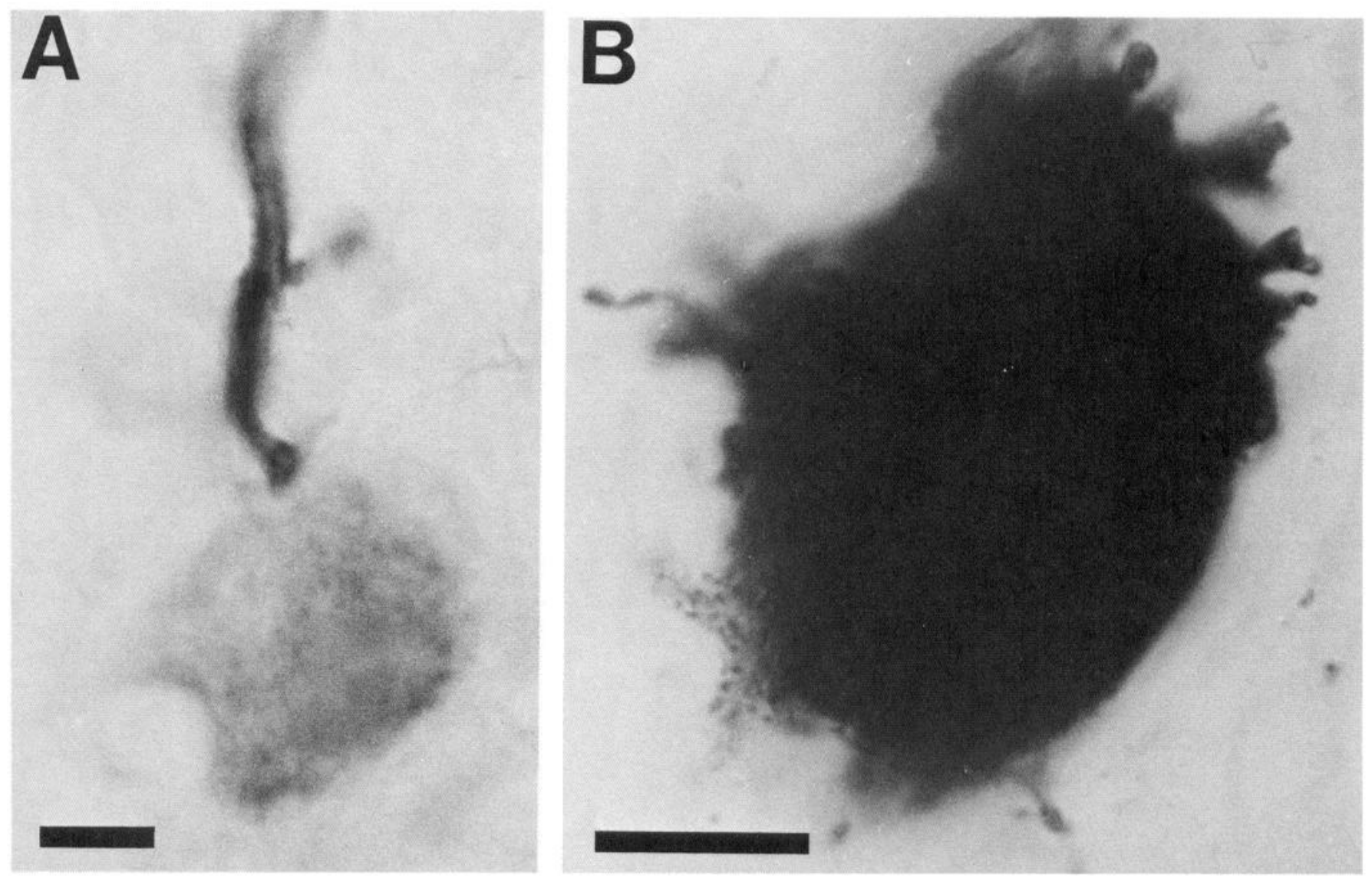

Figure 11. Magnocellular afferents and laminaris neurons. A, An HRP-labeled magnocellular afferent forms a large, club-shaped terminal on a laminaris neuron. Scale bar, $5 \mu \mathrm{m}$. B, A rapid Golgi impregnation of a laminaris neuron shows the large, oval soma surrounded by large numbers of short dendrites. Scale bar, $5 \mu \mathrm{m}$.

Table 2. Data for 12 laminaris neurons

\begin{tabular}{|c|c|c|c|c|c|c|c|c|c|c|}
\hline $\begin{array}{l}\text { Cell } \\
\text { number }\end{array}$ & $\begin{array}{l}\text { Frequency } \\
(\mathrm{Hz})\end{array}$ & $\begin{array}{l}\text { Contra- } \\
\text { lateral } \\
\text { vector } \\
\text { strength }\end{array}$ & $\begin{array}{l}\text { Contra- } \\
\text { lateral } \\
\text { phase }\left(^{\circ}\right)\end{array}$ & $\begin{array}{l}\text { Ipsi- } \\
\text { lateral } \\
\text { vector } \\
\text { strength }\end{array}$ & $\begin{array}{l}\text { Ipsi- } \\
\text { lateral } \\
\text { phase }\left({ }^{\circ}\right)\end{array}$ & $\begin{array}{l}\text { Predicted ITD } \\
\left(\mathrm{I}-\mathrm{C}^{\circ} \text { or }\right. \\
\left.\mathrm{C}-\mathrm{I}^{\circ}\right) \\
\end{array}$ & $\begin{array}{l}\text { Predicted ITD } \\
(\mu \mathrm{sec})\end{array}$ & $\begin{array}{l}\text { Observed } \\
\text { ITD } \\
(\mu \mathrm{sec})\end{array}$ & $\begin{array}{l}\text { Sponta- } \\
\text { neous rate } \\
\text { (\% max) }\end{array}$ & $\begin{array}{l}\text { Maxi- } \\
\text { mum } \\
\text { spike } \\
\text { rate }\end{array}$ \\
\hline 344021 & 5500 & 0.52 & 302 & 0.47 & 194 & -108 & -55 & -65 & 1 & 320 \\
\hline 320004 & 6060 & 0.43 & 52 & 0.12 & 13 & -39 & -18 & -18 & 1 & 380 \\
\hline 322010 & 5500 & 0.21 & 330 & 0.19 & 345 & 15 & 7 & 15 & 12 & 750 \\
\hline 320013 & 5847 & 0.21 & 297 & 0.13 & 207 & -90 & -43 & -31 & 27 & 350 \\
\hline 351001 & 4970 & 0.36 & 259 & 0.52 & 229 & -30 & -18 & -41 & 0 & 140 \\
\hline 351200 & 4409 & 0.67 & 338 & 0.61 & 294 & -44 & -28 & -45 & 0 & 180 \\
\hline 351250 & 6552 & 0.37 & 9 & 0.12 & 267 & $258 /-102$ & $109 /-44$ & -73 & 1 & 260 \\
\hline 351273 & 4551 & 0.46 & 251 & 0.45 & 106 & -145 & -88 & -50 & 18 & 450 \\
\hline 351275 & 4552 & 0.67 & 308 & 0.58 & 160 & -148 & -90 & -48 & 4 & 350 \\
\hline 351276 & 3554 & 0.56 & 169 & 0.57 & 329 & $160 /-200$ & $125 /-150$ & -141 & 0 & 620 \\
\hline 351277 & 1025 & 0.64 & 52 & 0.75 & 247 & $195 /-165$ & $530 /-447$ & $>-300$ & 18 & 490 \\
\hline 325001 & 4110 & 0.62 & 23 & 0.34 & 152 & $129 /-321$ & $87 /-156$ & -120 & 2 & 190 \\
\hline
\end{tabular}

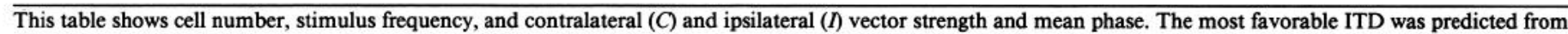

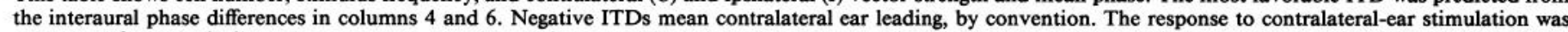

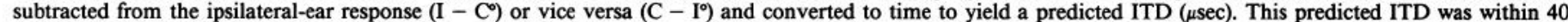

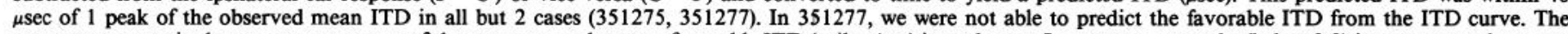

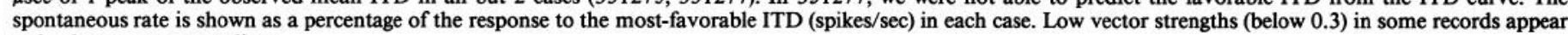
to be due to poor recordings. 

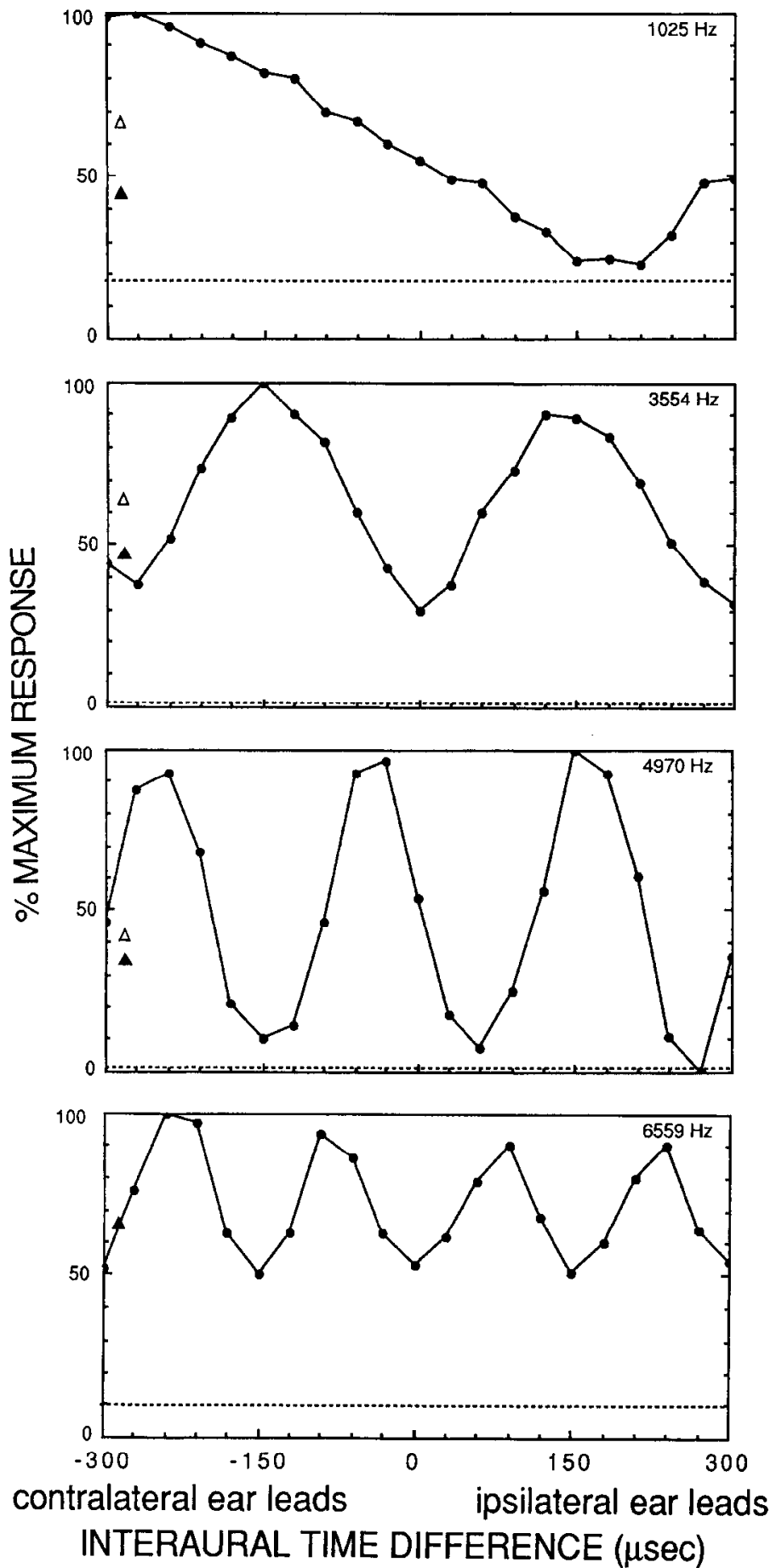

Figure 12. Interaural delay curves plot response of laminaris neurons against changing ITDs. Four laminaris neurons were selected to display a range of different responses, including best frequency, differences in spontaneous rate (dotted lines), and maximum peak-to-trough height. The numbers of spikes in each delay curve have been normalized to the maximum response. Open and solid triangles indicate contra- and ipsilateral monaural spike rates, respectively, normalized to the maximum binaural response.

lateral ear, being $56 \%$ of the binaural maximum $( \pm 16 \%, n=5)$ as opposed to $47 \%$ for the contralateral ear $( \pm 15 \%, n=5)$. The absolute number of spikes evoked by binaural stimulation may be found in Table 2. Some cells (322010, 320013, 351273, 351277 ) had higher spontaneous rates (about $20 \%$ of maximum) than the rest which were about $1 \%$ of the maximum rate.

\section{Other physiological properties of laminaris neurons}

Intracellular responses of laminaris neurons to monaural and binaural stimulation revealed that laminaris neurons fire tonically and at about half the rate [mean interspike interval (ISI) for ipsi- or contralateral stimuli $=7.3 \pm 3.8 \mathrm{msec}, n=10$ ] of magnocellular neurons (ISI $=3.6 \pm 1.0 \mathrm{msec}, n=25$; also compare Fig. 16 with Fig. 5). In response to binaural stimulation, the firing rate of laminaris neurons modulated between about twice the monaural rate (ISI $=5.0 \pm 1.9, n=4$ ) and the spontaneous rate (Table 2). Interspike interval histograms rcvealed an unusual feature of the laminaris neurons. In 9 of 10 laminaris neurons from which we measured interspike intervals, doublet spikes were observed in response to both monaural and binaural stimulation. These doublets may be seen in Figure $16 \mathrm{~A}$ and in the interspike interval histograms of Figure $16 C$. Doublets varied in numbers and in interval, occurring between 0.2 and $1 \mathrm{msec}$ apart (Fig. 16C).

Laminaris neurons exhibited greater vector strength in phaselocking to the auditory stimulus (Figs. 13, 14, Table 2) than magnocellular neurons. In a frequency-by-frequency comparison, and with the exception of the values below 0.2 in Table 2 , vector strength values for laminaris neurons fell above the regression lines in Figure $5 D$. In a small sample, laminaris neurons appeared to be as sharply tuned to frequency as their afferent inputs. Isointensity rate functions for both monaural and binaural stimuli were obtained for 3 laminaris neurons (Fig. $16 B$ ). In these neurons, stimulation of both ipsi- and contralateral ears produced overlapping curves with $50 \%$ bandwidths between $0.6-1.4 \mathrm{kHz}$. Binaural frequency responses at a favorable ITD were similar to those evoked by monaural stimulation (Hig. 16B).

\section{Discussion}

In the barn owl, the localization of sounds in azimuth requires the detection of ITDs. We have described the circuit in the nucleus laminaris responsible for detecting these ITDs and will discuss below the 4 essential features of this circuit. First, the elements of the circuit phase-lock in order to preserve timing information from the ear to the point of comparison. Second, afferent projections to the nucleus laminaris act as delay lines, and the topography of their projection in this nucleus creates maps of ITD. Third, coincidence detectors tap these delay lines and signal particular interaural time differences. Fourth, ITDs are place-coded for further processing by higher-order nuclei.

\section{Encoding of phase}

Phase-locked spikes encode the timing of the stimulus. The owl's auditory system uses this code for the measurement of time disparities and shows phase-locking up to $9 \mathrm{kHz}$, as opposed to about $3-5 \mathrm{kHz}$ in some mammals (Goldberg and Brownell, 1973; Crowe et al., 1978; Sullivan and Konishi, 1984). The eighth nerve, the nucleus magnocellularis, and the nucleus laminaris phase-lock to the auditory stimulus. Vector strength shows a small improvement between the eighth nerve and the nucleus magnocellularis (Sullivan and Konishi, 1984) and a marked improvement between the nucleus magnocellularis and the nucleus laminaris (this paper). The increases in vector strength may be the result of a 2:1 convergence of eighth-nerve inputs onto magnocellular neurons and a 100:1 convergence from the nucleus magnocellularis to the nucleus laminaris (C. E. Carr, unpublished observation). Increases in vector strength might 


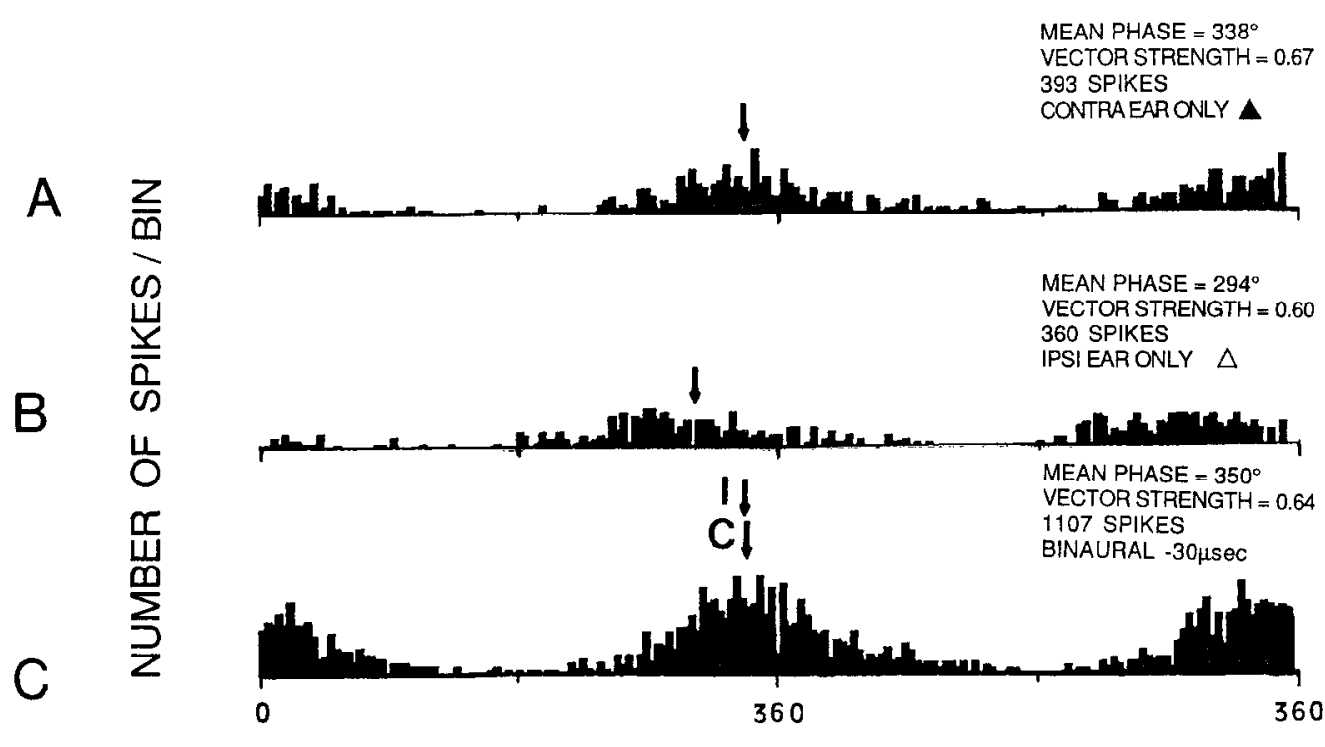

MEAN PHASE

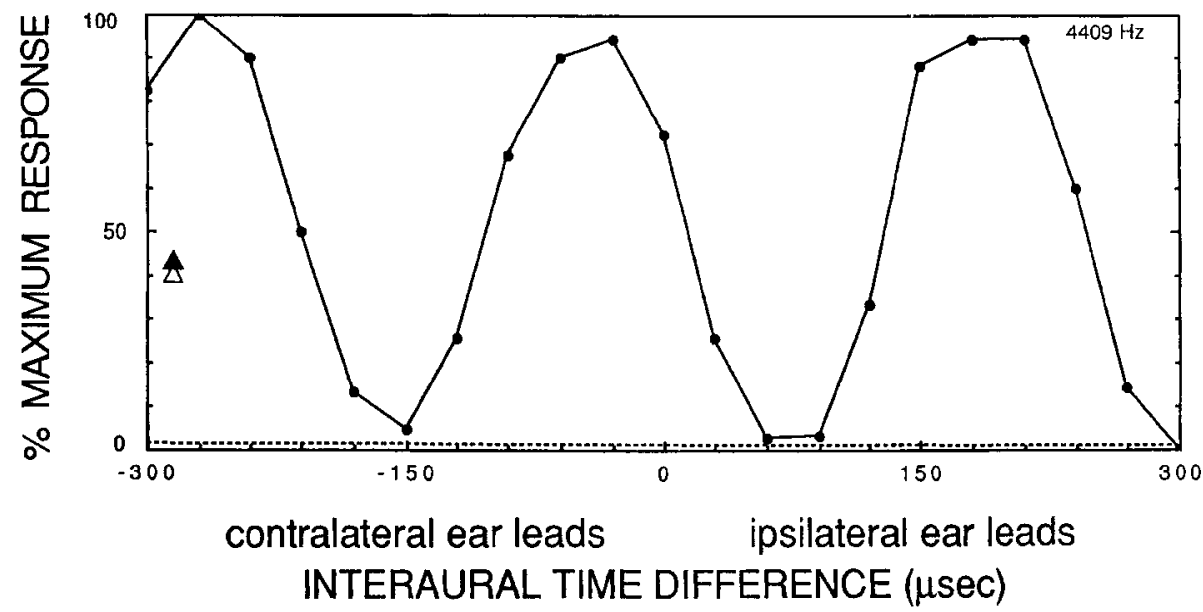

Figure 13. Period histograms and interaural delay curves for laminaris neuron 351200 , showing responses to contralateral ear $(A)$, ipsilateral ear $(B)$, and binaural stimulation $(C)$. The interaural delay curve is shown in $D$. $A$, Laminaris neuron 351200 stimulated with a $4409-\mathrm{Hz}$ tone yielded monaural responses to stimulation of the contralateral ear with a mean phase of $338^{\circ}$ (arrow) and a vector strength of 0.67 . Number of spikes, 393 for 100 repetitions of the stimulus. $B$, Stimulation of the ipsilateral ear yielded a period histogram with a mean phase of $294^{\circ}$ (arrow) and a vector strength of 0.60 . Number of spikes, 360 . C. Binaural stimulation where the contralateral led the ipsilateral ear by $30 \mu \mathrm{sec}$ (most-favorable ITD). The mean phase was $350^{\circ}$, the vector strength was 0.64 , and the number of spikes was 1107 . The vertical arrows marked $C$ and $I$ mark the expected time of arrival of the response to monaural stimulation of each ear, as derived from $A$ and $B$. $D$, Interaural delay curve obtained from tonal stimulation at $4409 \mathrm{~Hz}$. The spontaneous rate is indicated by a dashed line. The solid and open triangles show mean spike counts obtained separately for contralateral and ipsilateral stimulation, respectively, normalized to the maximum response evoked by the mostfavorable interaural delay. also be expected in the chick, where laminaris neurons receive between 25-35 magnocellular afferents (Hackett and Rubel, 1982). In mammals, neurons of the medial superior olive and the trapezoid body appear to show better phase locking than the primary auditory nerve (Yin and Chan, 1990), though a similar improvement in phase-locking was not found in comparisons of the anteroventral cochlear nucleus and the superior olivary complex in the kangaroo rat (Crowe et al., 1978).

\section{Anatomy and physiology of the delay lines}

The magnocellular afferents to the nucleus laminaris have been candidates for delay lines since the anatomical observations of Rubel and his colleagues (Parks and Rubel, 1975; Young and Rubel, 1983, 1986). They proposed that the projections from the nucleus magnocellularis to the nucleus laminaris in the chick acted as delay lines to measure ITDs for sound localization. The first physiological evidence that magnocellular afferents might be delay lines came from the work of Sullivan and Konishi (1986) in the barn owl. They measured "neurophonics," or toneinduced evoked potentials, which reflect the phase-locked firing in the nucleus laminaris. These recordings showed a systematic change in the phase of the response to stimulation of each ear as an electrode traveled through the nucleus, so that for ipsilateral stimulation, the phase delay increased with depth, and for contralateral stimulation, the phase delay decreased. The phase changes suggested that there is an orderly representation of interaural phase differences in the nucleus laminaris that reflects the phase differences between the 2 ears as a sound moves around the head.

The results of the neurophonic experiments were confirmed by the intracellular recordings from magnocellularis afferents in the nucleus laminaris (Carr and Konishi, 1988; this paper). Delays in the arrival time of phase-locked spikes from the ipsilateral afferents increased with depth, while the delays of the contralateral afferents decreased. A change in delay with depth would be expected as a simple consequence of conduction velocity and distance along any one axon, but in the nucleus laminaris, orderly changes in delay are seen in neighboring axons in the same penetration (Fig. 8). Thus, spike timing is synchronized among adjacent axons. Extracellular recording of these synchronized spikes in the magnocellular axons would appear as a neurophonic. When the orderly changes in phase are converted to 
Figure 14. Period histograms and interaural delay curve for laminaris neuron 351277 , showing responses to contralateral ear $(A)$, ipsilateral ear $(B)$, and binaural stimulation $(C, D)$. All plots are as in Figure 13. $A$, Laminaris neuron 351277 yielded monaural responses to stimulation with a $1025 \mathrm{~Hz}$ tone of the contralateral ear with a mean phase of $52^{\circ}$ (arrow) and a vector strength of 0.64 . Number of spikes, 1603 . Note that with a best frequency of $1025 \mathrm{~Hz}$, the period was $975 \mu \mathrm{sec}$. $B$, Stimulation of the ipsilateral ear yielded a period histogram with a mean phase of $247^{\circ}$ (arrow) and a vector strength of 0.75 . Number of spikes, 2253. $C$, Binaural stimulation where the contralatcral $(C)$ led the ipsilateral $(I)$ ear by $150 \mu \mathrm{sec}$. The mean phase was $12^{\circ}$, the vector strength was 0.78 , and the number of spikes was 2957 . D, Binaural stimulation where the ipsilateral $(I)$ ear led the contralateral $(C)$ ear by $100 \mu \mathrm{sec}$ (not a favorable ITD) and yielded a mean phase of $229^{\circ}$ and a vector strength of 0.16 , with 1017 spikes, well below the monaural response level. $E$, Interaural delay curve for a laminaris neuron obtained with a tonal stimulus of $1025 \mathrm{~Hz}$. The spontaneous rate is indicated by a dashed line. The solid and open triangles show mean spike counts obtained separately for ipsilateral and contralateral stimulation, respectively, normalized to the maximum response evoked by the most-favorable interaural delay.
A
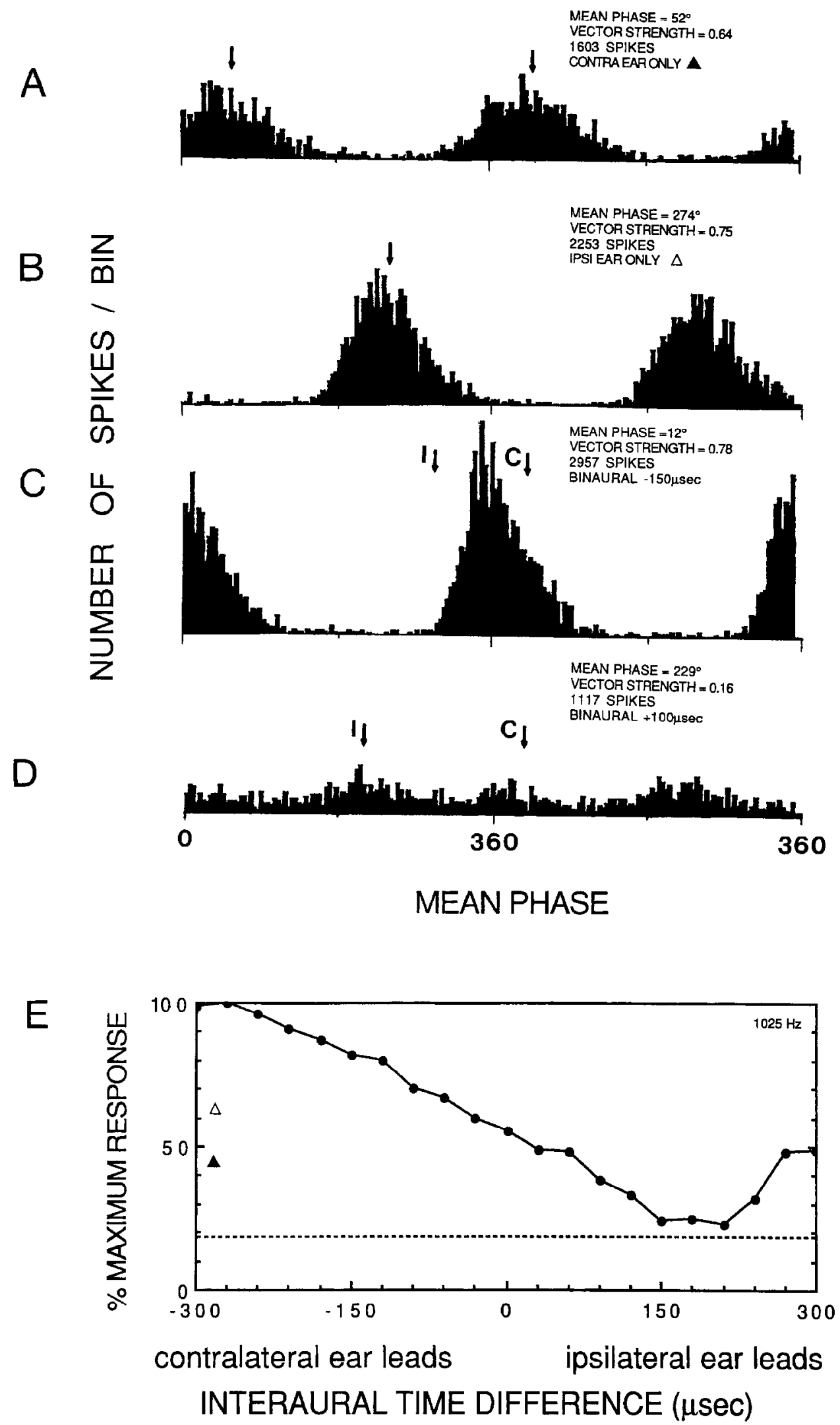

time, the arrival time of phase-locked spikes at a particular depth is similar in different isofrequency regions of the nucleus laminaris. These time differences are also comparable to the range of ITDs of about $200 \mu \mathrm{sec}$ available to the owl's auditory system (Moiseff, 1989b).
The amount of delay mapped in the nucleus laminaris is regulated both by the dorsoventral dimension of the nucleus and by the conduction velocity of the delay lines. Conduction velocities of 3-5 m/sec for 1-3- $\mu \mathrm{m}$-diameter fibers within the nucleus laminaris resemble those of unmyelinated rather than 
myelinated axons in the CNS (Waxman and Bennett, 1972). These low conduction velocities may be due to the short internodal distances within the nucleus laminaris. Magnocellularis fibers outside the nucleus laminaris present internodal distances of about $300 \mu \mathrm{m}$, while internodal distances shorten to about $60 \mu \mathrm{m}$ within the nucleus laminaris (Fig. 10). Closely spaced nodes of Ranvier in the electric organ of sternarchid fishes have a functionally significant role in the regulation of conduction velocity (Waxman et al., 1972). Such closely spaced nodes have also been identified in the teleost and mammalian CNS (Waxman and Melker, 1971). We hypothesize that these changes in internodal distance, plus changes in fiber diameter, form the substrate for the regulation of conduction velocity (i.e., delay) in the nucleus laminaris.

There are similarities and differences in the innervation of the nucleus laminaris between the owl and chicken. In both the barn owl and the chicken, the ipsilateral collaterals are all of similar length, while the contralateral collaterals increase in length along the mediolateral dimension of the nucleus laminaris. $\mathrm{Ru}$ bel and his associates have suggested that increasing interaural delays in the chicken might be represented by the increasing mediolateral path length within the contralateral projection (Parks and Rubel, 1975; Young and Rubel, 1983, 1986; Overholt et al., 1983). The nucleus laminaris is much thicker in the dorsoventral dimension in the owl than in the chicken, where the nucleus is composed of a monolayer of bipolar neurons that receive input from ipsi- and contralateral cochlear nuclei onto their dorsal and ventral dendrites, respectively. This pattern of delay lines contrasts with the multiple, dorsoventrally arranged delay lines in the barn owl. The hypertrophy of the nucleus laminaris in owls perhaps bears on their acute sense of directional hearing.

\section{Interaural phase sensitivity and coincidence detection}

Laminaris neurons are sensitive to ITDs (Moiseff and Konishi, 1983; Sullivan and Konishi, 1986). The cyclic nature of the interaural delay curve at the period of the stimulating tone indicates that the underlying mechanism is a sensitivity to the interaural phase disparity (Moiseff and Konishi, 1981). Because the auditory system uses interaural phase difference to measure ITD, in this paper we have generally referred to both interaural phase and interaural time differences as ITDs.

The use of phase-locked spikes for measurement of ITD requires that the scale for time measurement be the same for the 2 sides. The scale used here is the period length or its reciprocal, frequency, of the stimulus tone. The matching of frequency is necessary for both the discrimination between different sound sources and for the avoidance of binaural beats. The observed match in frequency between the ipsilateral and contralateral inputs to the laminaris neurons satisfies the above condition. Laminaris neurons show a phase disparity between the period histograms made separately for ipsilateral and contralateral stimulation. This binaural disparity is due to the difference between the ipsilateral and contralateral paths to the neuron. We have provided evidence that laminaris neurons fire maximally in response to an ITD that is the same magnitude as the binaural disparity, but opposite in sign. A neuron's favorable ITDs are thus predictable from its monaural period histograms. This finding indicates that laminaris neurons act as coincidence detectors, confirming an earlier conclusion of Sullivan and Konishi (1986). Coincidence detection in laminaris neurons is neither all nor nothing but graded; the discharge of a neuron declines from a

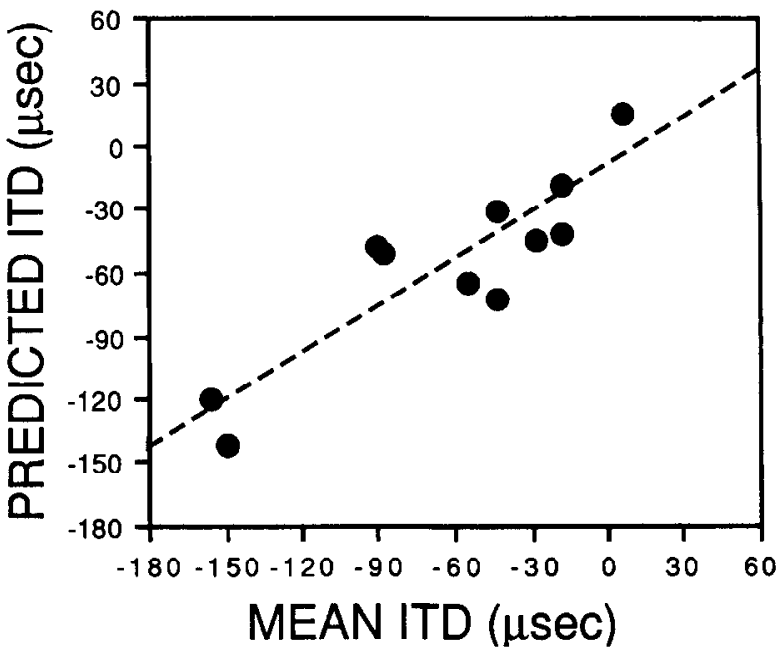

Figure 15. Correlation between mean ITD and ITD predicted from period histogram data in Table 2 . The mean peak position was calculated over a 90- $\mu \mathrm{sec}$ range above and below the ITD closest to the predicted ITD ( $n=11$ neurons). The regression line has a slope of 0.73 and a correlation coefficient of 0.79 .

maximum at the most-favorable interaural phase disparity to a minimum at the least-favorable interaural phase disparity according to a cosine-like function.

Similar coincidence detection of binaural stimuli has been reported from the neurons of the mammalian medial superior olive (Goldbcrg and Brown, 1969; Crowe et al., 1978; Yin and Chan, 1988, 1990). The general form of coincidence detection is cross correlation, and Yin and his colleagues have carried out quantitative tests of cross correlation in the medial superior olive (Yin and Chan, 1990) and identified some of the properties expected from the cross-correlation model. They also found similar properties in the inferior colliculus, which presumably acquires them relatively unchanged from the medial superior olive (Yin et al., 1987).

The behavior of both laminaris and medial superior olive neurons deviates from that of a cross correlator, however, because the neurons respond to monaural stimuli. The relationships between the magnitude of the response to monaural and binaural stimuli appear to be complex. In our sample of laminaris neurons, the number of spikes evoked by stimulation at the most-favorable ITD was about equal to the sum of monaural responses, while the response to the least-favorablc ITD was less than either of the monaural responses. Furthermore, the examination of phase-locking during binaural stimulation suggested that vector strength was highest during stimulation with the most-favorable ITD and lowest with the least-favorable ITD. Similar responses to the least-favorable ITD have been observed in the mammalian medial superior olive, and an inhibitory mechanism has been proposed to explain it (Goldberg and Brown, 1969; Moushegian et al., 1975; Yin and Chan, 1990). GABAergic terminals surround the neurons of the nucleus laminaris, but their role remains unknown (Carr et al., 1989). GABAmediated inhibition has been shown to reduce the magnitude of neuronal responses to ITD in all of the higher-order nuclei of the time-processing pathway, and the degree of inhibition may differ between favorable and unfavorable phase disparities (Fujita, 1988). 

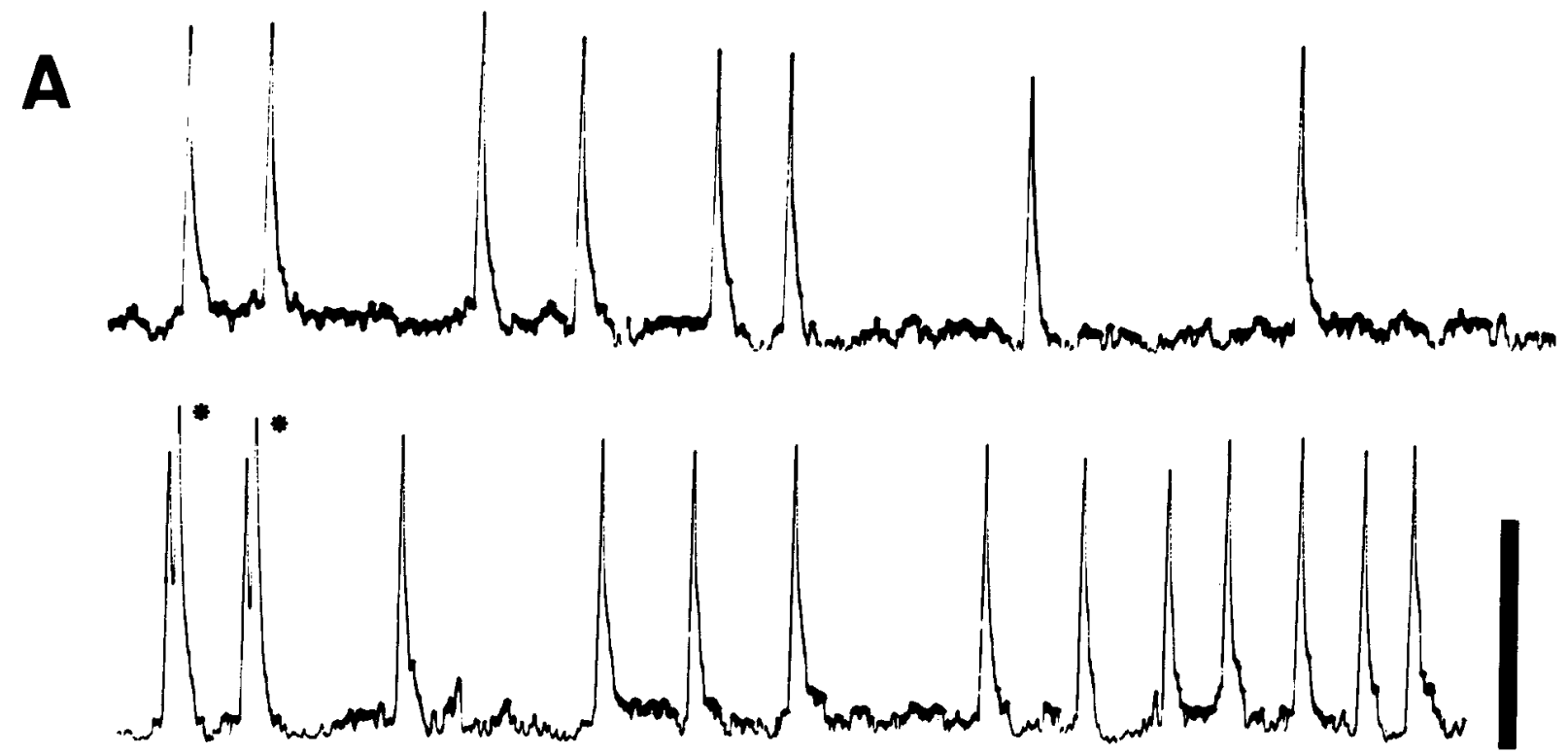

B
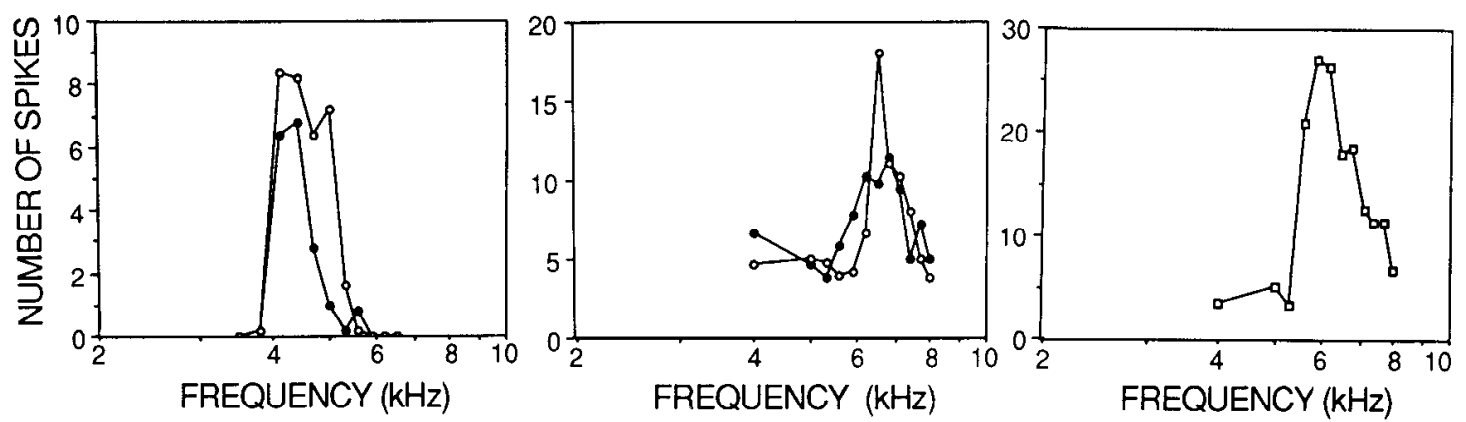

C
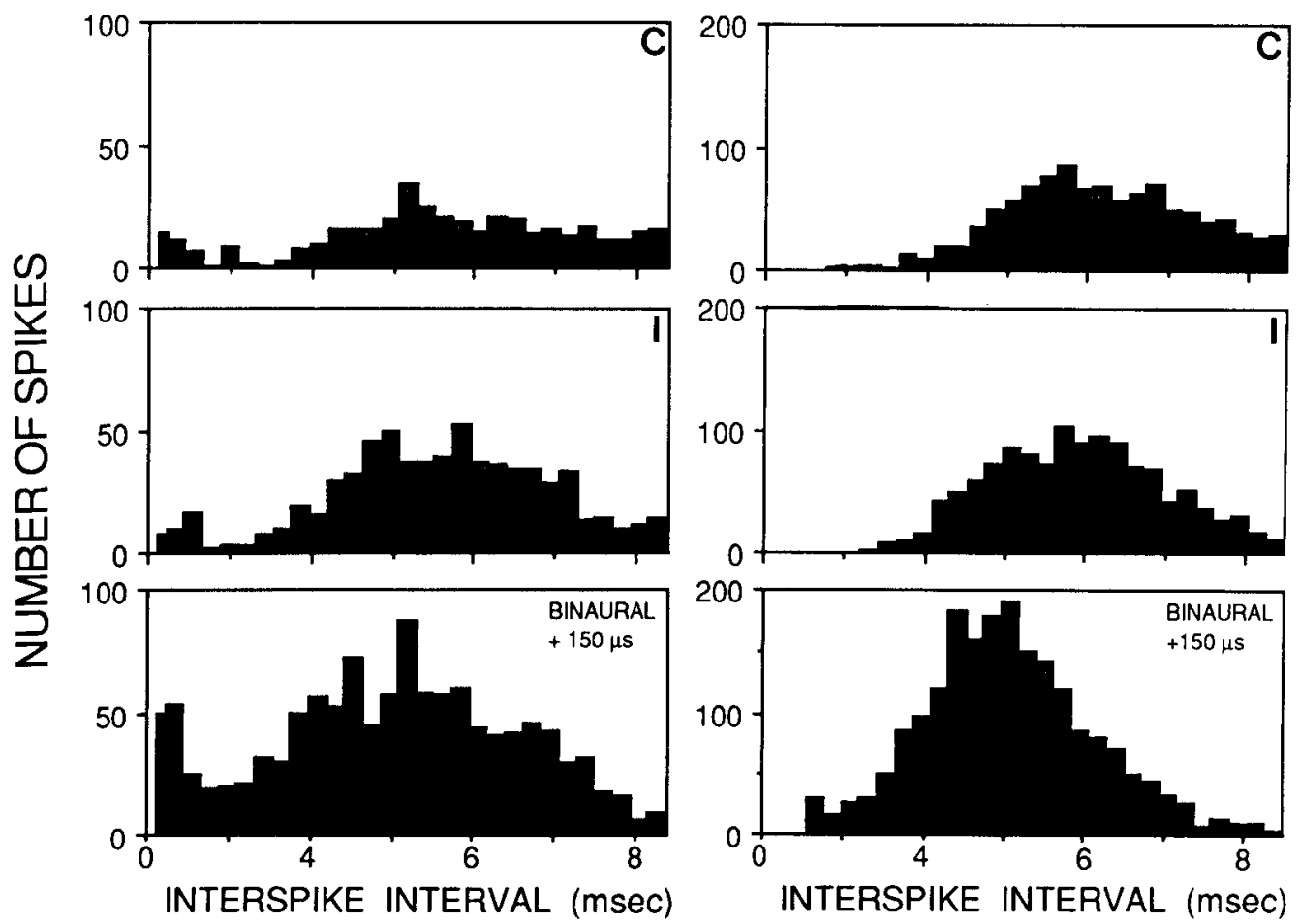


\section{Encoding of interaural time differences}

The Jeffress theory (Jeffress, 1948) explains not only how ITDs are measured, but also how they are encoded. The model contains an array of coincidence detectors receiving input by afferent axons serving as delay lines. In the model, each neuron of the array responds only to sound coming from a particular direction, and thus the anatomical "place" of the neuron encodes the location of the sound. We present below several lines of indirect evidence for place coding and for maps of ITD in the nucleus laminaris.

The transformation of a time code into a place code can be inferred from the absence of a time code in the neurons of the higher-order nuclei that receive direct input from the nucleus laminaris. Goldberg and Brown (1969) used a similar argument for place coding in the medial superior olive. Although phaselocking occurs in the axons of the nucleus laminaris that project to the central nucleus of the inferior colliculus and to the anterior subdivision of the lateral lemniscal complex, the ITD-sensitive neurons of these and other higher-order nuclei do not phaselock to the auditory stimulus (Moiseff and Konishi, 1983). This evidence indicates that spike timing does not encode ITD after the nucleus laminaris, and it follows that binaural coincidence detection of phase-locked spikes does not recur in the higherorder nuclei receiving direct or indirect inputs from nucleus laminaris. The neurons in these targets of the nucleus laminaris also do not display the morphological adaptations associatcd with phase-locking, such as the end-bulb synapses in nucleus magnocellularis, the very short dendrites of nucleus laminaris, or the presence of calcium-binding proteins (Maler et al., 1984; Takahashi et al., 1987; Takahashi and Konishi, 1988a, b). These lines of evidence support the hypothesis that neuronal selectivity for ITD in the higher-order nuclei is derived from a place code in nucleus laminaris by line labeling.

Labeled lines are seldom randomly distributed in the brain (Konishi, 1986). The laminaris projection zone in the central nucleus of the inferior colliculus contains maps of ITD in which the ITD selectivity of neurons changes systematically along the axis orthogonal to that of changes in best frequency (Wagner et al., 1987). In the nucleus laminaris, delays in spike conduction vary systematically in each isofrequency band, and the ITD selectivity of laminaris neurons is therefore likely to vary along the axis orthogonal to the tonotopic axis. This consideration and the orderly pattern of the anatomical projection from the nucleus laminaris to the central nucleus of the inferior colliculus suggest that the maps of ITD in the central nucleus are copies of those in the nucleus laminaris (Takahashi and Konishi, 1988a). A similar relationship between ITD and frequency selectivity appears to be present in the medial superior olive of the cat (Yin and Chan, 1990). In this nucleus, the tonotopic axis is oriented in the dorsoventral direction, and the most-favorable ITD appears to vary systematically along the anteroposterior direction, or orthogonal to the tonotopic axis.
It is interesting to point out that a locus in the third dimension of the nucleus laminaris, which runs mediolateral, projects to all parts of the corresponding isofrequency lamina in the central nucleus of the inferior colliculus, suggesting that no additional stimulus variable is mapped along that axis (Takahashi and Konishi, 1988a). Neurophonic measurements in the nucleus laminaris showed isodelay contours nearly parallel to the mediolateral axis of the nucleus (Sullivan and Konishi, 1986). These findings lend support to the hypothesis that each isofrequency lamina of the nucleus laminaris contains not one but a family of dorsoventrally oriented, parallel maps of ITD.

\section{Synthesis}

The owl's auditory system computes ITDs in a partly hierarchically organized pathway. The first step is the encoding of phase by the timing of spike discharge in the auditory nerve. The 2 cochlear nuclei separate phase and amplitude codes. The third step performs a cross-correlation-like operation on phaselocked spikes in separate frequency bands by using a special circuit composed of axonal delay lines and coincidence detector neurons. In this step, a new variable, ITD, emerges and becomes place coded. Two additional processes occur in higher-order nuclei: the enhancement of neuronal selectivity for ITD and the derivation of the real ITD from phase-ambiguous ITDs. The first process occurs within each frequency band in the central nucleus of the inferior colliculus. The second process involves convergence of different frequency channels on single neurons in the external nucleus of the inferior colliculus. Nonlinear interactions between different frequency channels allow the derivation of the real ITD or characteristic delay. GABAergic inhibition appears to mediate both of these processes. After all these steps, the time- and intensity-processing pathways converge upon each other to form a bicoordinate map of auditory space in the external nucleus of the inferior colliculus.

\section{References}

Adams JC (1981) Heavy metal intensification of DAB-based HRP reaction product. J Histochem Cytochem 29:775.

Anderson DJ, Rose JE, I lind JE, Brugge JF (1970) Temporal position of discharges in single auditory nerve fibers within the cycle of a sinewave stimulus: frequency and intensity effects. J Acoust Soc Am 49: 1131-1139.

Brawer JR, Morest DK (1975) Relations between auditory nerve endings and cell types in the cat's anteroventral cochlear nucleus seen with the Golgi method and Nomarski optics. J Comp Neurol 155: 251-299.

Calford MB, Piddington RW (1988) Avian interaural canal enhances interaural delay. J Comp Physiol 162:503-510.

Carr CE, Konishi M (1988) Axonal delay lines for time measurement in the owl's brainstem. Proc Natl Acad Sci USA 85:8311-8315.

Carr CE, Fujita I, Konishi M (1989) Distribution of GABAergic neurons and terminals in the auditory system of the barn owl. J Comp Neurol 286:190-201.

Crowe G, Rupert AL, Moushegian G (1978) Phase locking in monaural

\section{$\leftarrow$}

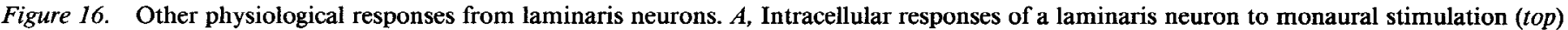

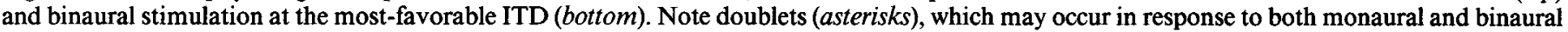

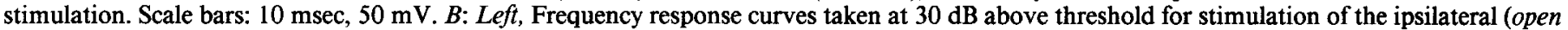

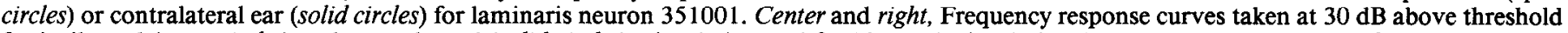

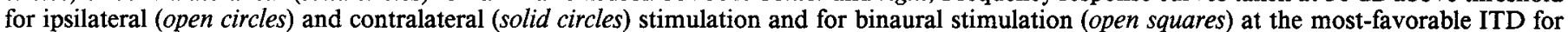

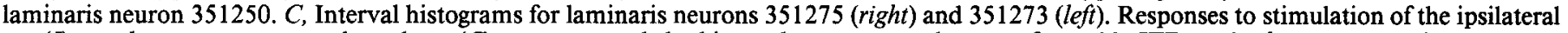

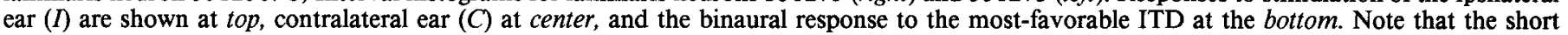
intervals associated with the spike doublets are found in both monaural and binaural responses in 351273. 
and binaural medullary neurons: implications for binaural phenomena. J Acoust Soc Am 64:493-501.

Cullheim S, Kellerth J-O (1978) A morphological study of the axons and recurrent axon collaterals of cat sciatic $\alpha$-motorneurons after intracellular staining with horseradish peroxidase. J Comp Neurol 178:537-558.

Curcio CA, Sloan KR (1986) Computer-assisted morphometry using video-mixed microscope images and computer graphics. Anat Rec 214:329-337.

Fujita I (1988) The role of GABA mediated inhibition in the formation of auditory receptive fields. Uehara Mem Life Sci Found Res Rep 2: 159-161 (in Japanese).

Goldberg JM, Brown PB (1969) Response of binaural neurons of dog superior olivary complex to dichotic tonal stimuli: some physiological mechanisms of sound localization. J Neurophysiol 32:613-636.

Goldberg JM, Brownell WE (1973) Discharge characteristics of neurons in anteroventral and dorsal cochlear nuclei of cat. Brain Res 64: $35-54$.

Guinan JJ Jr, Guinan SS, Norris BE (1972) Single auditory units in the superior olivary complex. I. Response to sound classifications based on physiological properties. Int J Neurosci 4:101-120.

Hackett JT, Rubel EW (1982) Synaptic excitation of the second and third order auditory neurons in the avian brain stem. Neuroscience 7:1455-1469.

Jeffress LA (1948) A place theory of sound localization. J Comp Physiol Psychol 41:35-39.

Knudsen EI (1983) Subdivisions of the inferior colliculus in the barn owl (Tyto alba). J Comp Neurol 218:174-186.

Konishi M (1973) How the owl tracks its prey. Am Sci 61:414-424.

Konishi M (1986) Centrally synthesized maps of sensory space. Trends Neurosci 9:163-168

Konishi M, Sullivan WE, Takahashi T (1985) The owl's cochlear nuclei process different sound localization cues. J Acoust Soc Am 78: 360-364.

Konishi M, Takahashi TT, Wagner H, Sullivan WE, Carr CE (1988) Neurophysiological and anatomical substrates of sound localization in the owl. In: Auditory function (Edelman GM, Gall WE, Cowan WM, eds), pp 721-745. New York: Wiley.

Licklider JCR (1959) Three auditory theories. In: Psychology: a study of science (Koch S, ed), pp 41-144. New York: McGraw-Hill.

Maler L, Jande SS, Lawson DEM (1984) Localization of vitamin Ddependent calcium binding protein in the electrosensory and electromotor systems of high frequency gymnotid fish. Brain Res 301:166170.

Manley GA, Köppl C, Konishi M (1988) A neural map of interaural intensity differences in the brain stem of the barn owl. J Neurosci 8: 2665-2676.

Moiseff A (1989a) Binaural disparity cues available to the barn ow for sound localization. J Comp Physiol 164:629-636.

Moiseff A (1989b) Bicoordinate sound localization by the barn owl. J Comp Physiol 164:637-644.

Moiseff A, Konishi M (1981) Neuronal and behavioral sensitivity to binaural time differences in the owl. J Neurosci 1:40-48.

Moiseff A, Konishi M (1983) Binaural characteristics of units in the owl's brainstem auditory pathway: precursors of restricted spatial receptive fields. J Neurosci 3:2553-2562.

Moushegian G, Rupert AL, Gidda JS (1975) Functional characteristics of superior olivary nucleus to binaural stimuli. J Neurophysiol 38: $1037-1048$.
Overholt EM, Hyson RL, Rubel EW (1988) In vitro physiological studies of a "place map" in $\mathrm{n}$. laminaris in the chick. Soc Neurosci Abstr 14:1096.

Parks TN, Rubel EW (1975) Organization and development of brain stem auditory nucleus of the chicken: organization of projections from n. magnocellularis to $n$. laminaris. J Comp Neurol 164:435-448.

Payne RS (1971) Acoustic localization of prey by barn owls (Tyto alba). J Exp Biol 54:535-573.

Sereno MI (1985) Tectoreticular pathways in the turtle, Pseudemys scripta. I. Morphology of tectoreticular axons. J Comp Neurol 233: 48-90.

Sullivan WE, Konishi M (1984) Segregation of stimulus phase and intensity coding in the cochlear nucleus of the barn owl. J Neurosci 4:1787-1799.

Sullivan WE, Konishi M (1986) Neural map of interaural phase difference in the owl's brainstem. Proc Natl Acad Sci USA 83:84008404.

Takahashi T, Konishi M (1986) Selectivity for interaural time difference in the owl's midbrain. J Neurosci 6:3413-3422.

Takahashi T, Konishi M (1988a) The projections of the cochlear nuclei and nucleus laminaris to the inferior colliculus of the barn owl. J Comp Neurol 274:190-211.

Takahashi T, Konishi M (1988b) The projections of nucleus angularis and nucleus laminaris to the lateral lemniscal nuclear complex of the barn owl. J Comp Neurol 274:212-238.

Takahashi T, Carr CE, Brecha N, Konishi M (1987) Calcium binding protein-like immunoreactivity labels the terminal field of nucleus laminaris of the barn owl. J Neurosci 7:1843-1856.

Wagner H, Takahashi T, Konishi M (1987) Representation of interaural time difference in the central nucleus of the barn owls' inferior colliculus. J Neurosci 7:3105-3116.

Waxman SG, Bennett MVL (1972) Relative conduction velocities of myelinated and non-myelinated fibers in the central nervous system. Nature 238:217-219.

Waxman SG, Melker RJ (1971) Closely spaced nodes of Ranvier in the mammalian brain. Brain Res 32:445-448.

Waxman SG, Pappas GD, Bennett MVL (1972) Morphological correlates of functional differentiation of nodes of Ranvier along single fibers in the neurogenic electric organ of the knife fish Sternachus. J Cell Biol 53:210-224.

Yin TCT, Chan JCK (1988) Neural mechanisms underlying interaural time sensitivity to tones and noise. In: Auditory function (Edelman GM, Gall WE, Cowan WM, eds), pp 385-430. New York: Wiley.

Yin TCT, Chan JCK (1990) Interaural time sensitivity in the medial superior olive of the cat. J Neurophysiol, in press.

Yin TCT, Kuwada S (1983) Binaural interaction in low-frequency neurons in inferior colliculus of the cat. III. Effects of changing frequency. J Neurophysiol 50:1020-1042.

Yin TCT, Chan JCK, Carney LII (1987) Effects of interaural time delays of noise stimuli on low-frequency cells in the cat's inferior colliculus. III. Evidence for cross-correlation. J Neurophysiol 58:562583.

Young SR, Rubel EW (1983) Frequency specific projections of individual neurons in chick brain stem auditory nuclei. $J$ Neurosci 3 : 1373-1378.

Young SR, Rubel EW (1986) Embryogenesis of arboration pattern and topography of individual axons in $\mathrm{n}$. laminaris of the chicken brain stem. J Comp Neurol 254:425-459. 